\title{
Upregulated Interleukin 21 Receptor Enhances Proliferation and Epithelial-Mesenchymal Transition Process in Benign Prostatic Hyperplasia
}

OPEN ACCESS

Edited by:

Michal Masternak,

University of Central Florida,

United States

Reviewed by:

Claudio Acuña-Castillo, Centro de Biotecnología Acuícola, Universidad de Santiago de Chile,

Chile

James Harper,

Sam Houston State University,

United States

*Correspondence:

Xinhua Zhang

zhangxinhuad@163.com

tThese authors have contributed equally to this work

Specialty section:

This article was submitted to

Endocrinology of Aging,

a section of the journal

Frontiers in Endocrinology

Received: 26 September 2018 Accepted: 07 January 2019

Published: 23 January 2019

Citation:

$X$ U D, Chen P, Xiao H, Wang $X$,

DiSanto ME and Zhang X (2019) Upregulated Interleukin 21 Receptor

Enhances Proliferation and Epithelial-Mesenchymal Transition

Process in Benign Prostatic Hyperplasia. Front. Endocrinol. 10:4. doi: 10.3389/fendo.2019.00004

\section{Deqiang $\mathrm{Xu}^{1 \dagger}$, Ping Chen ${ }^{1 \dagger}$, He Xiao ${ }^{1 \dagger}$, Xinghuan Wang ${ }^{1}$, Michael E. DiSanto ${ }^{2}$ and Xinhua Zhang ${ }^{1 *}$}

${ }^{1}$ Department of Urology, Zhongnan Hospital of Wuhan University, Wuhan, China, ${ }^{2}$ Department of Surgery and Biomedical Sciences, Cooper Medical School of Rowan University, Camden, NJ, United States

Background: Interleukins (ILS) and related chronic inflammation have been found to contribute to the development of benign prostatic hyperplasia $(\mathrm{BPH})$ in recent decades. As a late member of the ILs family, IL-21 receptor (IL-21R) can modulate cell proliferation, however, IL-21R activity in the prostate has not been examined. The current study aimed to elucidate a potential role of IL-21R in the development of BPH.

Material and Methods: Human prostate tissues, cell lines and rats were used. QRT-PCR, Western blot, and immunohistochemistry, along with hematoxylin and eosin, Masson's trichrome, and immunofluorescent staining were performed. $\mathrm{BPH}-1$ cells with IL-21R silenced were cultured or co-cultured with macrophages (active THP-1, AcTHP-1). Apoptosis and cell cycle phases were determined via flow cytometry. Epithelial-mesenchymal transition (EMT) processes were also examined. In vivo, rat prostatitis was induced with intraprostatic injected lipopolysaccharide (LPS).

Results: IL-21R was highly expressed in human as well as rat prostate, mainly in the epithelial compartment. BPH concomitant with prostatitis significantly upregulated the expression of IL-21R. Knockdown of IL-21R induced cell apoptosis and cycle arrest at G0/G1 phase, and blocked the EMT process in BPH-1 cells. When IL-21R silenced $\mathrm{BPH}-1$ cells were co-cultured with AcTHP-1 cells, these aforementioned processes and IL-21R change were completely reversed. Prostatic hyperplasia was observed with IL-21R upregulated in LPS induced prostatitis rats. More specifically, the expression of apoptosis, cyclin, and EMT proteins in this rat model are altered in a manner consistent with that seen in the cell line model.

Conclusions: Our novel data demonstrates the expression and functional activities of $\mathrm{IL}-21 \mathrm{R}$ in the mechanism for development of $\mathrm{BPH}$. IL-21R mainly localized in prostate epithelium and it was upregulated in hyperplastic prostate tissues. IL-21R enhanced proliferation of $\mathrm{BPH}-1$ cells, via inhibiting cell apoptosis, and modulating cell cycles, as well as the EMT process, in response to inflammatory stimuli.

Keywords: benign prostatic hyperplasia, prostatitis, inflammation, interleukin 21 receptor, cell apoptosis, cell cycle, epithelial-mesenchymal transition 


\section{INTRODUCTION}

Benign prostatic hyperplasia $(\mathrm{BPH})$ is a common urinary tract disease in aging men (1), resulting in lower urinary tract symptoms (2). The incidence is close to $50 \%$ among men over the age of 50 and $80 \%$ among men over the age of 80 (3). Age and androgens are considered necessary for the pathogenesis of $\mathrm{BPH}$ (4), while the exact etiology of $\mathrm{BPH}$ remains unclear. In recent decades, many hypotheses have been proposed suggesting that androgens-to-estrogens ratio imbalance, stromal-epithelial interactions, growth factors, and metabolic syndrome including obesity and diabetes, likely play important roles in the onset and progression of $\mathrm{BPH}$. Recent evidence suggested that $\mathrm{BPH}$ development involves accumulation of mesenchymal-like cells derived from the prostatic epithelium by epithelial-mesenchymal transition (EMT) (5-7). Meanwhile, it has been also hypothesized that $\mathrm{BPH}$ is an immune-mediated inflammatory disease and chronic inflammation may directly stimulate the development of $\mathrm{BPH}$ (8-10). Clinically, most BPH patients often concomitantly have prostatitis $(10,11)$. Inflammatory infiltrates of $\mathrm{BPH}$ tissues may lead to tissue damage, a chronic process of wound healing, tissue remodeling, and prostate growth $(12,13)$. Histologically, there are often many infiltrating lymphocytes and macrophages around the glandular elements of BPH tissues (14). These infiltrating cells produce cytokines to stimulate epithelial and stromal proliferation (15). Indeed, Robert et al. (16) found that macrophages are one of the major inflammatory infiltrates in $\mathrm{BPH}$ specimens as determined by histological analysis, suggesting macrophages are crucial for promoting BPH development and progression via secretion of inflammatory factors. Meanwhile, profound EMT features were observed in an LPS-induced prostatitis and $\mathrm{BPH}$ rat model (17).

Interleukins (ILs) are the main lymphatic cytokines with multiple biological activities and have important regulatory roles in the development, differentiation, and immune response of immune cells as well as the activation of other cells. In recent decades, IL-21 and its receptor IL-21R were identified and newly added to the ILs system $(18,19)$, which shares a similar structure to the other members of this family (20). Binding of IL-21 to the IL-21R activates the Janus-faced kinase/signal transducer and activator of transcription (JAK/STAT) pathways and plays important roles in enhancing cell proliferation (21). IL-21R is preliminarily expressed on hematopoietic cells and regulates the proliferation of mature $\mathrm{B}$ and $\mathrm{T}$ cells in response to stimuli (19). However, studies have shown IL-21R is also expressed on non-immune cells such as fibroblasts, endothelial cells, keratinocytes, and Hodgkin lymphoma cells $(22,23)$. A recent study showed IL-21 and its receptor play an important role in breast cancer cells via proliferation, migration, and invasion (20), suggesting IL-21R could contribute to other diseases via similar mechanisms. Since BPH occurs due to the imbalance of

Abbreviations: BPH, benign prostatic hyperplasia; ILs, interleukins; IL-2R, interleukin 2 receptor; IL-21R, interleukin 21 receptor; AcTHP-1, active THP1; EMT, epithelial-mesenchymal transition; LPS, lipopolysaccharide; H \& E, Hematoxylin and Eosin; JAK/STAT, Janus-faced kinase/signal transducer and activator of transcription; qRT-PCR, quantitative real-time PCR; SM, smooth muscle; E-Cad, E-cadherin; N-Cad, N-cadherin; SD, standard deviation. cell proliferation and cell apoptosis, as well as immune-mediated chronic inflammation as aformentioned, IL-21 and its receptor IL-21R could play a permissive role in the development of BPH. Indeed, elevated levels of ILs have been found in BPH tissues when compared to normal prostate tissues including IL-1, IL6 , and IL-8 $(24,25)$. Overexpression of IL-15/IL-15R in the prostate has been found in $\mathrm{BPH}$ patients when compared to their controls (26).Moreover, recent studies have suggested that both prostatic epithelial and stromal cells can express ILs, including IL-1, IL-2, IL-4, IL-6, IL-8, IL-12, IL-13, IL-15, IL-17, IL-18, and IL-23, in response to inflammatory stimuli. Subsequently these ILs were found to regulate the growth of epithelial and stromal cells $(15,27)$, indicating ILs play important roles in the onset and progression of $\mathrm{BPH}$. Although the production of these ILs result in the abnormal growth in the prostate, the primary initiators during the development of $\mathrm{BPH}$ are not yet known.

Nevertheless, the expression and functions of IL-21R in the prostate have never been determined. In the current study, we examined the expression and functional activities of IL$21 \mathrm{R}$ in prostate tissues and human prostate cell lines. We hypothesized that IL-21R would respond to inflammatory stimuli from macrophages and play an important role in the onset and progression of $\mathrm{BPH}$, via inhibiting apoptosis, modulation of cell cycle progression and the EMT process, which would provide a new molecular target for BPH therapy.

\section{MATERIALS AND METHODS}

\section{Animals and Tissues}

A total of 16 male Sprague-Dawley rats (12 weeks old) were used and randomly divided into two groups. Rats were anesthetized with pentobarbital sodium, and then the lower abdomen was incised to expose the prostates. Subsequently, PBS $(200 \mu \mathrm{l})$ or LPS (200 $\mu \mathrm{g} / \mathrm{kg}$, Sigma, St. Louis, MO, USA) (17) was injected equally into the right and left prostate lobes in PBS (control;

TABLE 1 | Primer sequence used for qPCR.

\begin{tabular}{ll} 
Target gene & Primer sequence \\
\hline HUMAN & \\
IL-21R & \\
Forward & $5^{\prime}$-GGCAAGACCAGTATGAAGAGC-3' \\
Reverse & $5^{\prime}$-TGACACTGAAAATGTCGTCGG-3' \\
GAPDH & \\
Forward & $5^{\prime}$-ATCCCATCACCATCTTCCAGGAG-3' \\
Reverse & $5^{\prime}$-CCTGCTTCACCACCTTCTTGATG-3' \\
RAT & \\
IL-21R & \\
Forward & \\
Reverse & $5^{\prime}$-GACCTGGAGTGAGTGGAGTG-3' \\
GAPDH & $5^{\prime}$-TAGCCTCCAAGGCAGATGGT-3' \\
Forward & \\
Reverse & $5^{\prime}$-ACAGCAACAGGGTGGTGGAC-3' \\
\hline
\end{tabular}


A
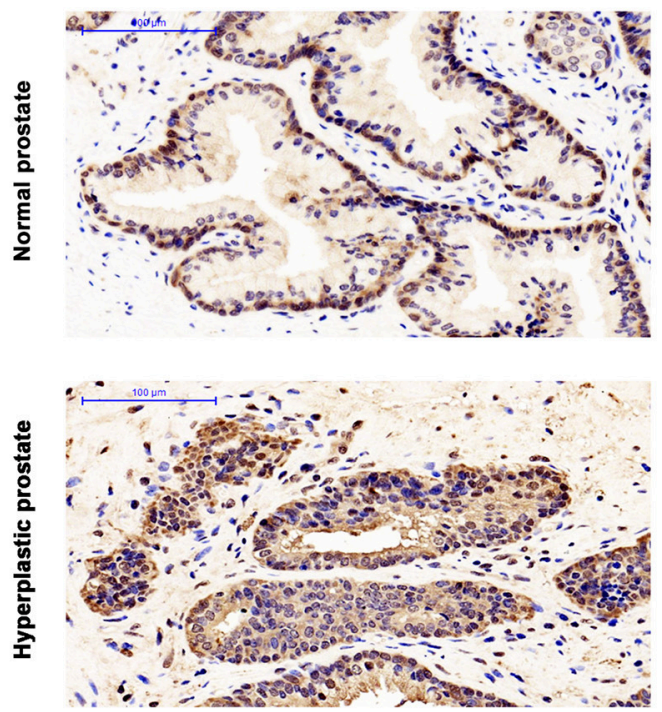

C

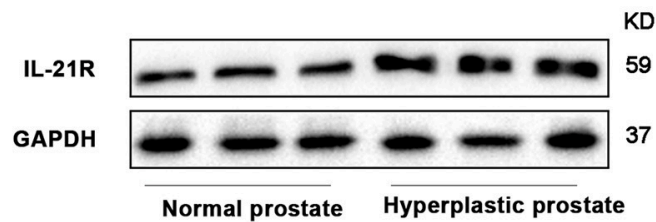

B

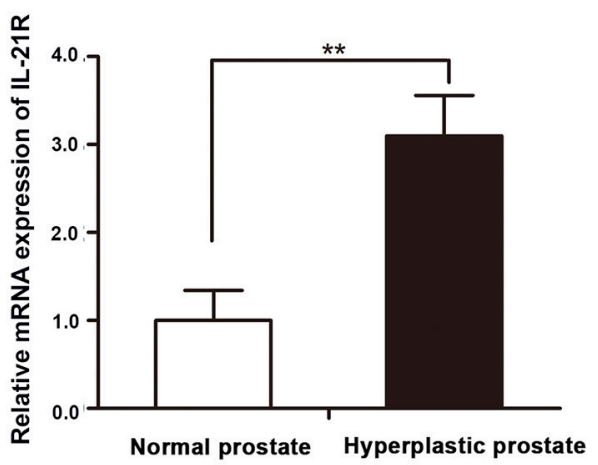

D

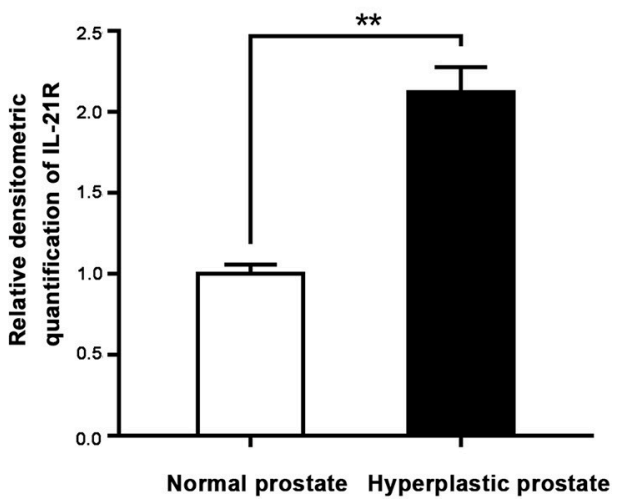

FIGURE 1 | Localization and expression of IL-21R in human prostate. (A) Immunohistochemistry of IL-21R in human prostate. Upper, Normal prostate; Lower, Hyperplastic prostate. IL-21R mainly distributed in epithelium. The scale bars are $100 \mu \mathrm{m}$; (B) the mRNA expression of IL-21R in human prostate ( $n=15$ for each group). Bars, $\pm \mathrm{SD} ;{ }^{\star \star} P<0.01$ vs. normal prostate. (C) Representative Western Blot band of IL-21R in human prostate. (D) Relative densitometric quantification of IL-21R in human prostate. GAPDH expression was analyzed as a loading control, results are expressed as ratio of IL-21R in respect to GAPDH. Boxes, mean; bars, \pm SD; ${ }^{\star \star} P<0.01$ vs. normal prostate.

$n=8)$ and LPS groups $(n=8)$, respectively. On the 14 th day after injection, rat prostates were excised, weighed, and used for the following experiments. Fifteen prostate samples from young brain-dead men (mean age, $28.2 \pm 4.4$ years old) undergoing organ donation were obtained as controls and 15 BPH samples were obtained from patients (mean age, $69.4 \pm$ 5.7 years old) undergoing cystoprostatectomy for infiltrating bladder cancer without prostate infiltration. Post-operative prostate pathology examinations revealed $\mathrm{BPH}$ concomitant with chronic prostatitis. All human samples were obtained after the approval of the Hospital Committee for Investigation in Humans and after receiving written informed consent from all patients or their relatives. Prostate tissues were divided into two strips and were, respectively, stored in liquid nitrogen for PCR analysis and Western blotting analysis and stored in $10 \%$ neutral buffered formalin for histological examination and immunofluorescence microscopy. All animal protocols were approved by the Animal Experiment Center of Zhongnan Hospital of Wuhan University and human studies were conducted in accordance with the principles of the Declaration of Helsinki.

\section{Cell Culture}

Human benign prostatic enlargement epithelia cell line BPH-1 (Cat. \#BNCC339850) was purchased from the Procell Co., Ltd. in Wuhan, China. Identification of the cell lines was performed at the China Center for Type Culture Collection in Wuhan, China. SV40 large-T antigen-immortalized stromal cell line WPMY1 (Cat. \#GNHu36) was purchased from the Stem Cell Bank, Chinese Academy of Sciences in Shanghai, China. Human acute monocytic leukemia cell line THP-1 (SCSP-567) was obtained from Stem Cell Library of Chinese Academy of Sciences. The 
A

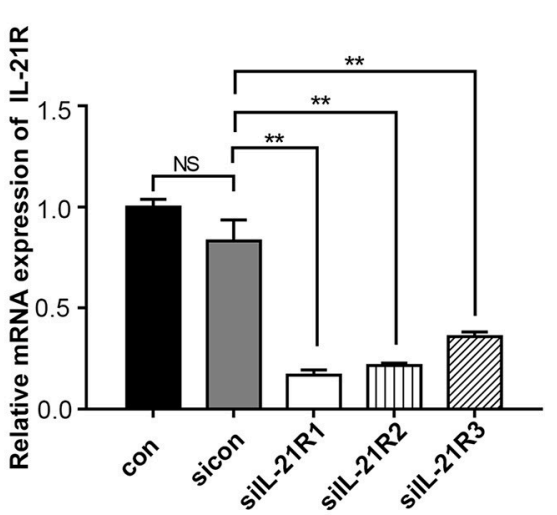

D
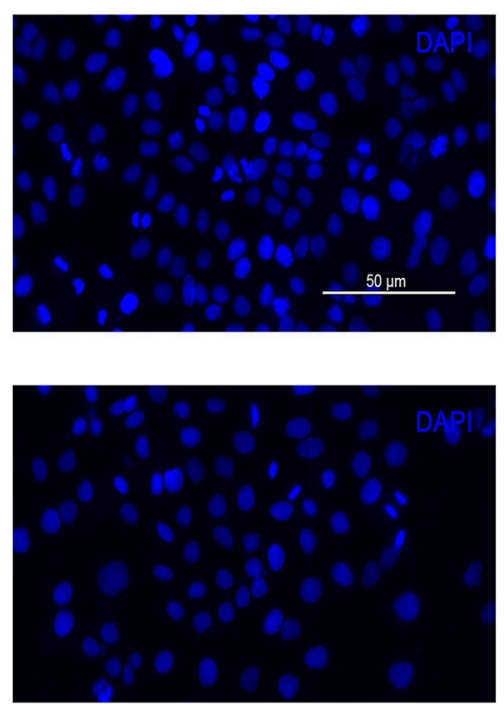

B
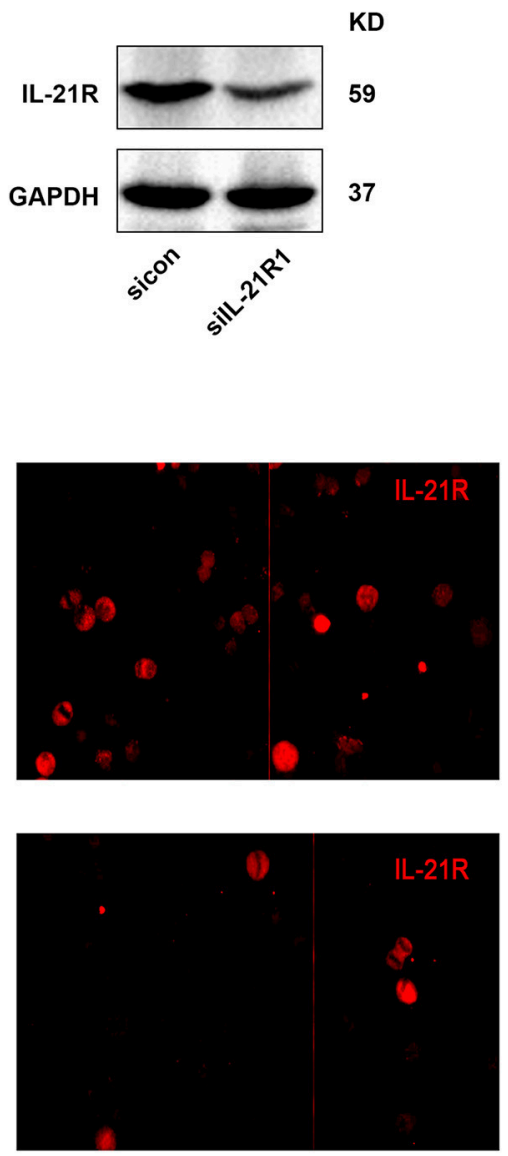

C
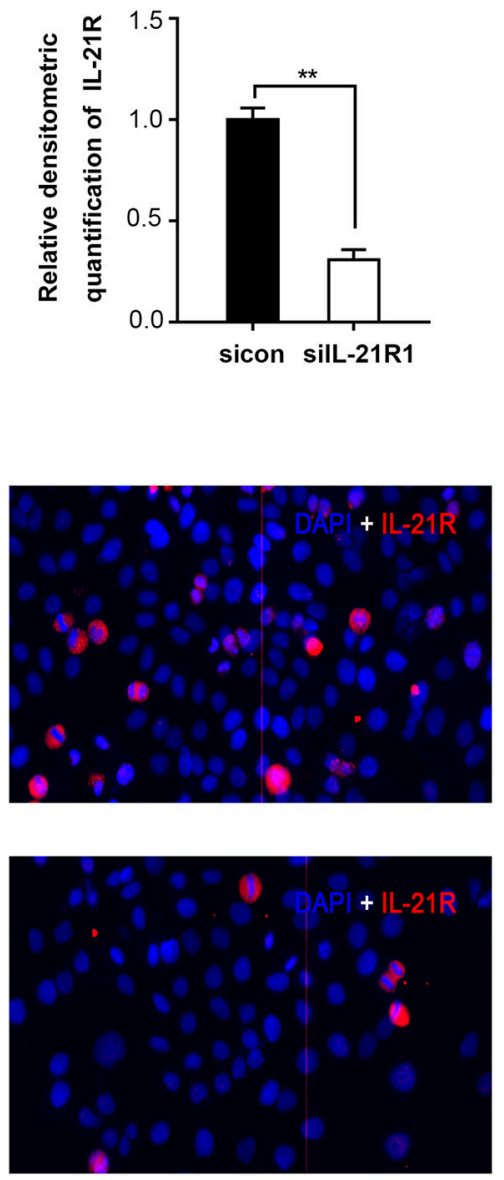

FIGURE 2 | Knockdown of IL-21R in BPH-1 cells with siRNA. (A) Knockdown efficiency of IL-21R in the mRNA levels in BPH-1 cells with three different siRNA sequences (silL-21R 1, 2, and 3). Boxes, mean; bars, \pm SD; con = control; NS means no significance, ${ }^{\star \star} P<0.01$ vs. control-siRNA (sicon). (B) Representative Western Blot band of IL-21R in BPH-1 cells treated with silL-21R of the highest inhibitory efficiency (sill-21R1) and sicon. (C) Relative densitometric quantification of IL-21R in BPH-1 cells. GAPDH expression was analyzed as a loading control, results are expressed as ratio of IL-21R in respect to GAPDH. Boxes, mean; bars, \pm SD; ${ }^{\star \star} P<0.01$ vs. sicon. (D) Immunofluorescence of IL-21R in BPH-1 cells treated with silL-21R1 and sicon. Cy3-immunofluorescence (red) indicates IL-21R expression. DAPI (blue) indicates cell nuclear staining. Merged image indicates of IL-21R and DAPI. The scale bars are $100 \mu \mathrm{m}$.

BPH-1 cells were cultured in RPMI-1640 medium (Gibco, China) containing 10\% fetal bovine serum (FBS) (Gibco, Australia). The WPMY-1 cells were cultured in DMEM medium (Gibco, China) containing $1 \%$ penicillin $\mathrm{G}$ sodium/streptomycin sulfate and 5\% FBS. The THP-1 cells were cultured in Opti medium with $10 \%$ inactivated FBS, the THP- 1 cells were differentiated into macrophages (active THP-1, AcTHP-1) using $10 \mathrm{ng} / \mathrm{ml}$ LPS for $24 \mathrm{~h}$. All the cell lines were cultured in a humidified atmosphere consisting of $95 \%$ air and $5 \% \mathrm{CO}_{2}$ at $37^{\circ} \mathrm{C}$.

\section{SiRNA and Transfection}

The cells were transiently transfected with siRNA using Lipofectamine transfection reagent. When the BPH-1 cells were $30-50 \%$ confluent in six-well culture plates, the cell culture medium was replaced with fresh RPMI-1640 medium $30 \mathrm{~min}$ before transfection. The transfection media were prepared according to the manufacturer's instructions and incubated at room temperature for $10 \mathrm{~min}$. Subsequently, $200 \mu \mathrm{l}$ of the lipofectamine complex solution was added to each well. After incubation for $6 \mathrm{~h}$ at $37^{\circ} \mathrm{C}$ in $5 \% \mathrm{CO}_{2}$, the cell culture medium was replaced with fresh RPMI-1640 medium and incubated for $48 \mathrm{~h}$. The GFP fluorescence was evaluated as a reporter for the transfection efficiency. The sequence of each siRNA is summarized in Supplementary Table S1.

\section{Co-culture Experiments}

Six-well transwell plates (Corning Inc., Corning, NY, USA) were used for co-culture experiments. THP- 1 cells $\left(1 \times 10^{6}\right.$ cells $)$ were differentiated into AcTHP-1 in the upper insert $(0.4 \mu \mathrm{m})$ of sixwell transwell plates containing $500 \mu \mathrm{l}$ of Opti medium with $10 \mathrm{ng} / \mathrm{ml}$ LPS for $24 \mathrm{~h}$. BPH- 1 cells $\left(3 \times 10^{5}\right.$ cells) were seeded in the lower chamber of six-well transwell plates containing $1.5 \mathrm{ml}$ 
of RPMI-1640 with 10\% FBS medium. The two cell lines were cocultured for $48 \mathrm{~h}$ in a humidified atmosphere consisting of $95 \%$ air and $5 \% \mathrm{CO}_{2}$ at $37^{\circ} \mathrm{C}$.

\section{Flow Cytometry Analysis}

For cell cycle analysis, BPH- 1 cells $\left(1 \times 10^{6}\right.$ cells $)$ were harvested, washed with PBS, and then centrifuged. Pellets were resuspended with $1 \mathrm{ml}$ DNA staining solution, which contained $50 \mu \mathrm{g} / \mathrm{ml}$ propidium iodide and $0.1 \mathrm{mg} / \mathrm{ml} \mathrm{RNaseA}$, and $10 \mu \mathrm{l}$ permeabilization solution. The DNA content distribution was analyzed by flow cytometry analysis (Beckman, Cat. \#FC500) after incubation in the dark at $37^{\circ} \mathrm{C}$ for $30 \mathrm{~min}$. For cell apoptosis analysis, FITC Annexin V Apoptosis Detection Kit I (BD Biosciences, USA) was used. BPH- 1 cells $\left(1 \times 10^{6}\right.$ cells $)$ were harvested and then stained with FITC Annexin V Apoptosis Detection Kit I according to the manufacturer's instruction.

\section{MTT Assays}

Three thousand BPH-1 cells were plated in each well of 96-well plates. Exactly $20 \mu \mathrm{l}$ of $5 \mathrm{mg} / \mathrm{ml}$ MTT solution was added to each well on day $0,1,2,3$ and 4 , and the cells were incubated for $4 \mathrm{~h}$ at $37^{\circ} \mathrm{C}$ in an incubator. The media was then removed and $150 \mu \mathrm{l}$ of DMSO was added. The plates, covered with tinfoil, were shaken on an orbital shaker for $10 \mathrm{~min}$. The readings were recorded by a microplate reader (Cat. \#SpectraMax M2, Molecular Devices, Sunnyvale, CA, USA) at an absorbance of $490 \mathrm{~nm}$ and reported as relative cell proliferation values.

\section{RNA Extraction and Quantitative Real-Time PCR (qRT-PCR) Analysis}

Total RNA was isolated from frozen tissues and cell lines using Trizol reagent (Invitrogen, Carlsbad, CA, USA) according to the manufacturer's instructions and quantitated at 260/280 $\mathrm{nm}$ using a NanoPhotometer spectrophotometer (IMPLEN, Westlake Village, CA, USA). Two $\mu \mathrm{g}$ of total RNA was reversetranscribed to complementary DNA (cDNA) via the SuperScript II First-Strand Synthesis System according to the manufacturer (Invitrogen). QRT-PCR was performed to determine the level of mRNA expression of a gene of interest based on SYBR green using a Bio-Rad (Hercules, CA, USA) CFX96 system. The expression levels of genes were normalized to the expression of GAPDH mRNA and compared by $2^{-\Delta \Delta C T}$ method. Primer sequences are listed in Table 1. All samples were independently repeated for analysis three times.

\section{Western Blot Analysis}

Tissues and BPH-1 cells were lysed and ultrasonicated in RIPA reagent containing protease inhibitor and phosphatase inhibitor (Sigma-Aldrich) on ice for $30 \mathrm{~min}$. After centrifugation at $12,000 \times \mathrm{g}$ for $15 \mathrm{~min}$, supernatant was collected. Thirty $\mu \mathrm{g}$ of total protein was separated via a $10 \%$ sodium dodecyl sulfate-polyacrylamide gel (SDS-PAGE) and transferred to polyvinylidene fluoride membrane (Millipore, Billerica, MA, USA) using a Bio-Rad wet transfer system. The membranes were blocked in TBST (Tris-buffered saline with $0.05 \%$ Tween 20) containing $5 \%$ non-fat dry milk at room temperature for $2 \mathrm{~h}$ and then incubated with primary antibodies (listed in

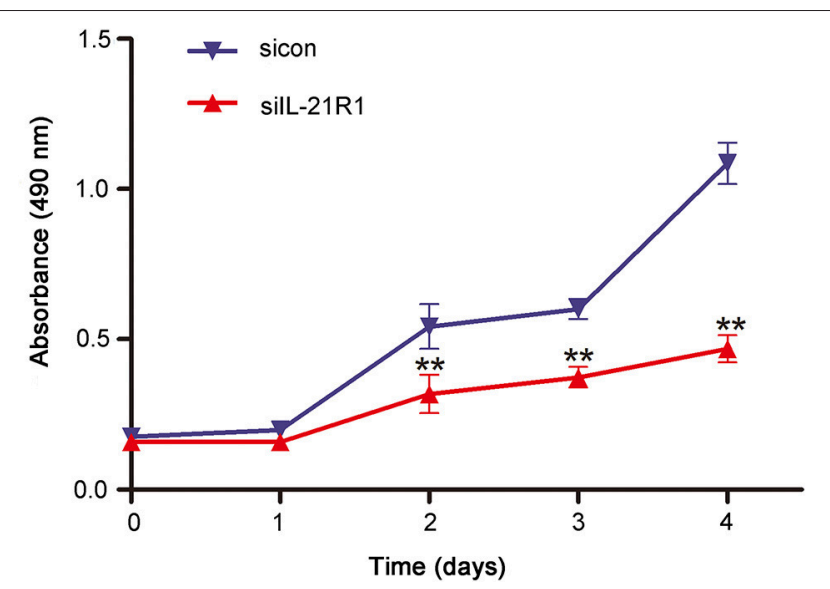

FIGURE 3 | Effect of knockdown of IL-21R on BPH-1 cell proliferation. Viability of $\mathrm{BPH}-1$ cells treated with silL-21R1 and sicon from day 0 until day 4 was analyzed by MTT assays. MTT assays was performed at the absorbance at $490 \mathrm{~nm}$. The $X$ axis indicates times, the $Y$ axis indicates the absorbance of $\mathrm{BPH}-1$ cells at $490 \mathrm{~nm}$. Bars, $\pm \mathrm{SD}$; ${ }^{\star \star} P<0.01$ vs. sicon.

Supplementary Table S2) overnight at $4^{\circ} \mathrm{C}$. After washing for three to five times with TBST, the membranes were incubated with secondary antibody (listed in Supplementary Table S3) at room temperature for $2 \mathrm{~h}$. Detection of reaction antigen was performed with an enhanced chemiluminescence kit (Thermo Scientific Fisher, Waltham, MA, USA). The bands were quantified by Quantity One ${ }^{\circledR}$ 1-D Analysis software (Bio$\mathrm{Rad})$. The expression levels of protein were normalized to the expression of GAPDH. All samples were independently repeated three times and means determined.

\section{Hematoxylin and Eosin (H \& E) Staining}

Prostate paraffin sections $(5 \mu \mathrm{m})$ were deparaffinized in xylene for $3 \times 10 \mathrm{~min}$, rehydrated in descending concentrations of ethanol $(100 \%, 96 \%, 80 \%, 70 \%)$ and $\mathrm{H}_{2}$ - O. The sections were then stained in $10 \%$ Hematoxilin (Sigma-Aldrich) for $7 \mathrm{~min}$, followed by washing under the tap water for $10 \mathrm{~min}$ to reveal the nuclei. Afterwards, the sections were stained in 1\% Eosin (SigmaAldrich) containing $0.2 \%$ glacial acetic acid for $5 \mathrm{~min}$. After staining, the sections were washed with tap water, dehydrated in increasing grades of ethanol $(70 \%, 80 \%, 96 \%, 100 \%)$, and cleared in xylene for $3 \times 10 \mathrm{~min}$. The sections were imaged by an inverted phase contrast microscope (Cat. \#DMI 1, Leica, Wetzlar, Germany).

\section{Masson's Trichrome Staining}

As previously described (28), prostate tissues were embedded into paraffin after being fixed in $10 \%$ formalin for $24-36 \mathrm{~h}$ and cut into $5 \mu \mathrm{m}$ sections. Then, the sections were stained using Masson's trichrome staining. Staining was detected by light microscopy. Prostatic smooth muscle (SM) cells, collagen fibers, and epithelial cells were stained red, blue, and orange, respectively. In each sample, we analyzed three areas randomly under magnification $(\times 200)$. The area percentage of SM, collagen 


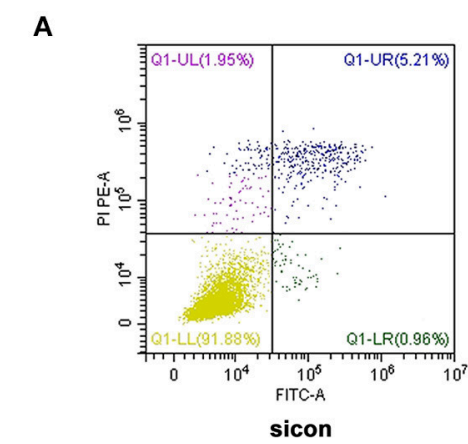

C

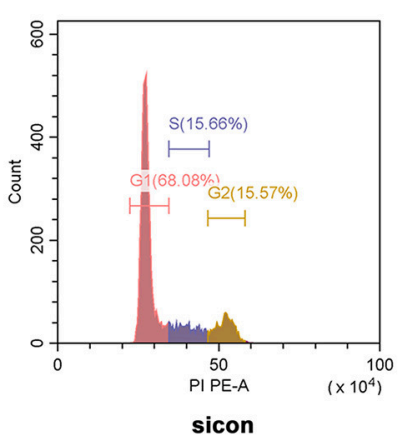

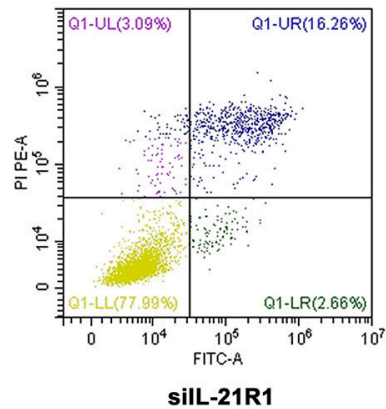

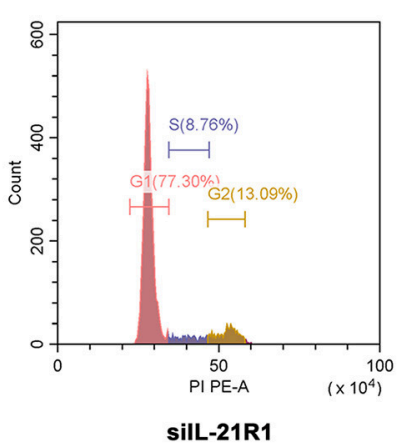

B

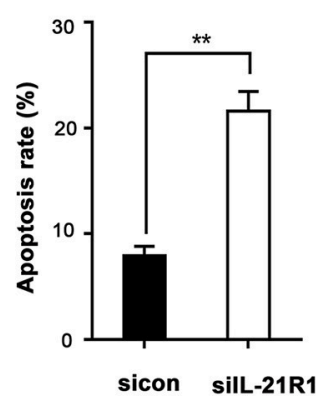

D

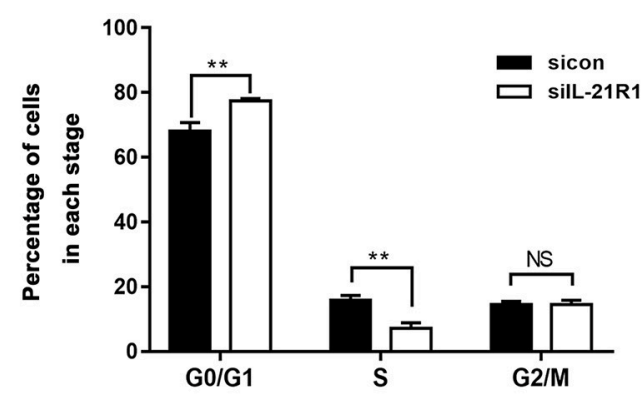

E

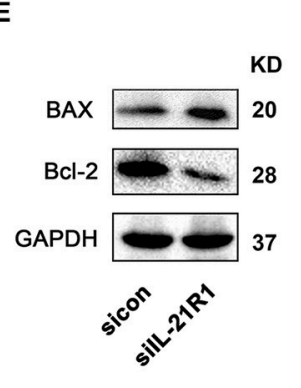

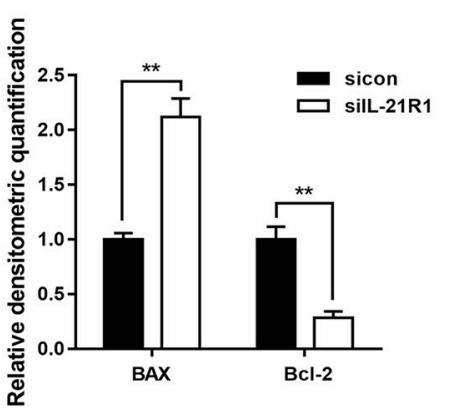

F
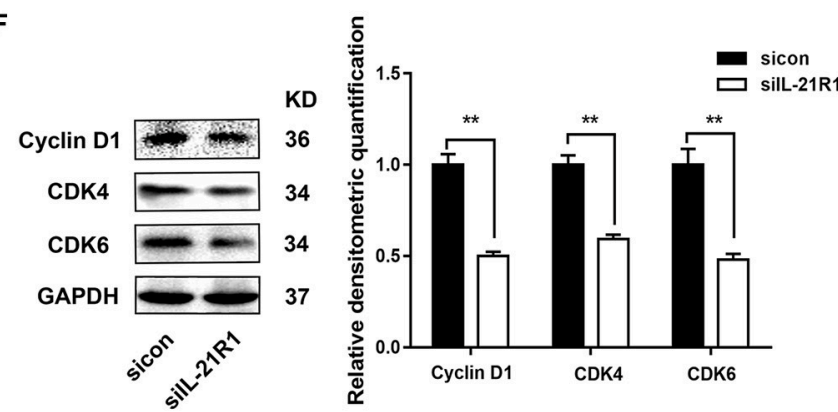

FIGURE 4 | Effect of knockdown of IL-21R on BPH-1 cell apoptosis and cell cycle. (A) Flow Cytometry analyses for cell apoptosis in BPH-1 cells treated with silL-21R1 and sicon. (B) Bar graph for apoptosis rate of BPH-1 cells. Boxes, mean; bars, $\pm \mathrm{SD}$; ${ }^{\star \star} P<0.01$ vs. sicon. (C) Flow Cytometry analyses for cell cycle in $\mathrm{BPH}-1$ cells treated with silL-21R1 and sicon. (D) Bar graph for the percentage of BPH-1 cells in each stage. Boxes, mean; bars, $\pm \mathrm{SD}$; ${ }^{\star \star} P<0.01$ vs. sicon. (E) Left, Representative Western Blot band of cell apoptosis associated proteins (BAX and Bcl-2) in BPH-1 cells. Right, Relative densitometric quantification of cell apoptosis associated protein (BAX and $\mathrm{Bcl}-2$ ) in $\mathrm{BPH}-1$ cells. GAPDH expression was analyzed as a loading control, results are expressed as ratio of the proteins in respect to GAPDH. Boxes, mean; bars, \pm SD; ${ }^{\star \star} P<0.01$ vs. sicon. (F) Left, Representative Western Blot band of cell cycle associated protein (Cyclin D1, CDK4, and CDK6) in $\mathrm{BPH}-1$ cells. Right, Relative densitometric quantification of cell cycle associated protein (Cyclin D1, CDK4, and CDK6) in BPH-1 cells. GAPDH expression was analyzed as a loading control, results are expressed as ratio of the proteins in respect to GAPDH. Boxes, mean; bars, $\pm \mathrm{SD} ;{ }^{\star \star} P<0.01$ vs. sicon.

fibers, and glandular epithelium were quantitated with Image Pro Plus 5.0.

\section{Immunohistochemistry Staining}

Tissues were embedded into paraffin after being fixed in $10 \%$ formalin for $24-36 \mathrm{~h}$ and cut into $5 \mu \mathrm{m}$ sections. The sections were then deparaffinized in xylene and rehydrated using descending grades of alcohols (100\%, 95\%, 70\%, 30\%). Antigen retrieval was performed by heating the sections in $10 \mathrm{mM}$ sodium citrate buffer at $\mathrm{pH} 6.0$ and at $96^{\circ} \mathrm{C}$ for $30 \mathrm{~min}$. Endogenous peroxidase activity was blocked using PBS containing 3\% hydrogen peroxide for $15 \mathrm{~min}$. Nonspecific binding was blocked by incubating the sections in
$5 \%$ normal donkey serum with $2 \%$ BSA for 1 h. The sections were then incubated overnight at $4{ }^{\circ} \mathrm{C}$ with rabbit anti-IL$21 \mathrm{R}$ antibodies (1:100; Abcam) followed by incubation with secondary antibodies at room temperature for $1 \mathrm{~h}$. Horse radish peroxidase polymer conjugate (Invitrogen, Carlsbad, CA, USA) was used to localize the antibody bound to antigen, with diaminobenzidine as the final chromogen. All immunostained sections were lightly counterstained with hematoxylin and immunostaining was detected by light microscopy.

\section{Immunofluorescent Staining}

Tissues were frozen and sectioned in $5 \mu \mathrm{m}$ thick slices and thawmounted onto glass slides using a cryostat (Leica CM 1850, 


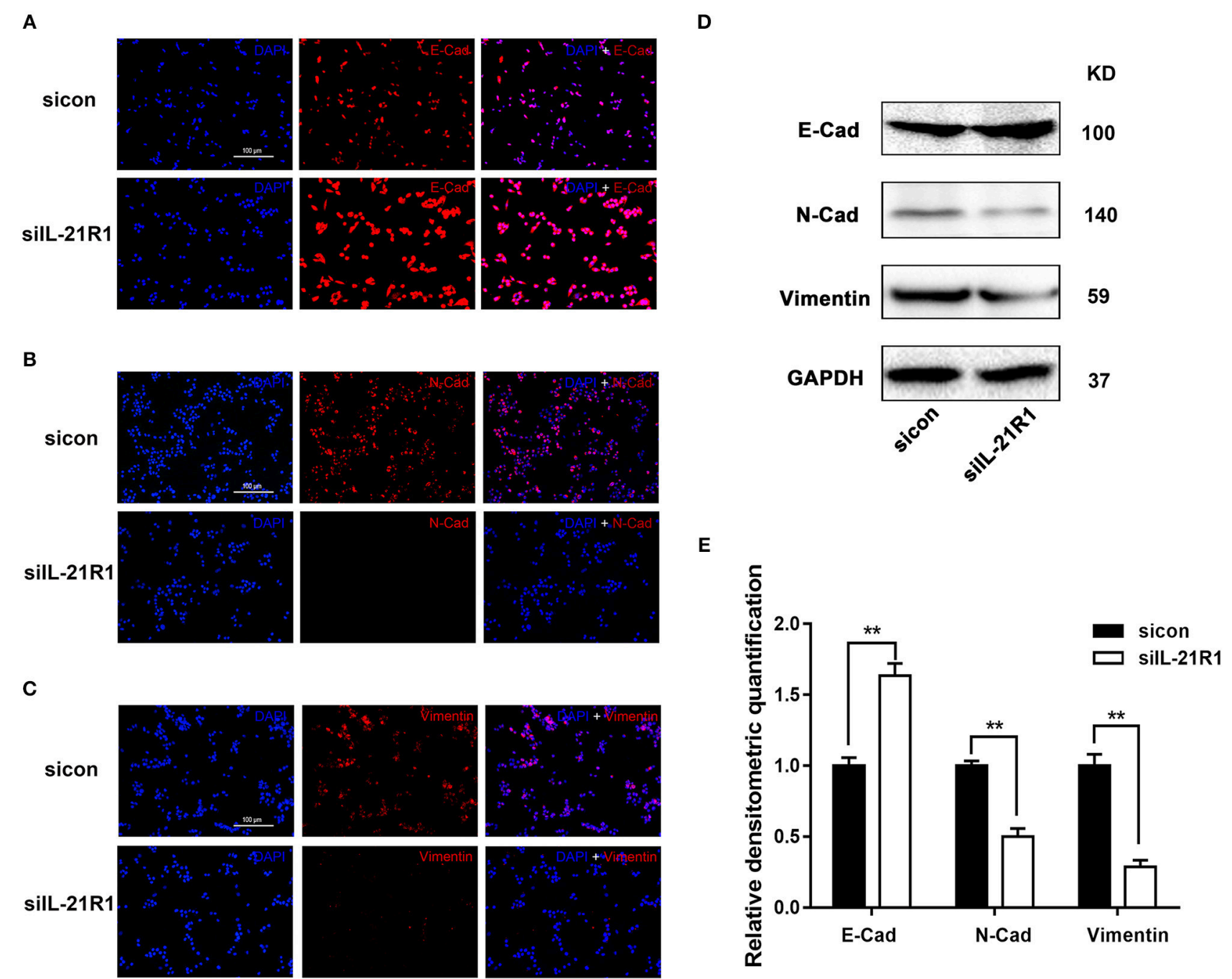

FIGURE 5 | Effect of knockdown of IL-21R on EMT process in BPH-1 cells. (A-C) Immunofluorescence of E-Cad, N-Cad, and vimentin in BPH-1 cells treated with silL-21R1 and sicon. Left, DAPI (blue) indicates cell nuclear staining. Middle, Cy3-immunofluorescence (red) indicates E-Cad (A), N-Cad (B), and vimentin (C) expression. Right, Merged image. The scale bars for (A-C) are $100 \mu \mathrm{m}$. (D) Representative Western Blot bands of EMT associated protein (E-Cad, N-Cad, and vimentin) in $\mathrm{BPH}-1$ cells. (E) Relative densitometric quantification of EMT associated proteins (E-Cad, N-Cad, and vimentin) in BPH-1 cells. GAPDH expression was analyzed as a loading control, results are expressed as ratio of the proteins in respect to GAPDH. Boxes, mean; bars, $\pm \mathrm{SD}$; ${ }^{\star \star} P<0.01$ vs. sicon.

Wetzlar, Germany), air-dried, and fixed for $10 \mathrm{~min}$ in ice cold acetone. BPH-1 cells $\left(6 \times 10^{5}\right.$ cells $)$ treated as described above were re-cultured on glass slides in six-well culture plates for $24 \mathrm{~h}$, washed with PBS three times and fixed with $4 \%$ formaldehyde at room temperature for $30 \mathrm{~min}$. Tissue and cell slides were then washed in PBS and incubated for $2 \mathrm{~h}$ in a mixture of PBS supplemented with $0.2 \%$ Triton $\mathrm{X}-100$ and $0.1 \%$ bovine serum albumin. After incubation overnight with the monoclonal antibodies rabbit anti-IL-21R (1:100; Abcam, Cambridge, MA), rabbit anti-E-cadherin (anti-E-Cad), anti-N-cadherin (anti-NCad), and anti-vimentin (all 1:100; all Bioworld Technology, Atlanta, GA, USA) at $4^{\circ} \mathrm{C}$, slides were incubated with FITClabeled secondary antibody (1:1,000; Santa Cruz Biotechnology, Santa Cruz, CA) for $1 \mathrm{~h}$ at room temperature. DAPI was used for staining the nucleus. Stained tissues and cells were viewed by fluorescence microscopy (PerkinElmer Life Sciences, Akron, OH, USA).

\section{Statistical Analysis}

The data values were expressed as the means \pm standard deviation $(S D)$. Statistical analysis was performed using nonparametric tests and one-way analysis of variance (ANOVA). Difference was considered statistically significant at $P<0.05$.

\section{RESULTS}

Immunohistochemical staining found IL-21R was predominantly localized in the epithelial compartment of human prostate with slight staining observed in the stroma (Figure 1A). Moreover, IL-21R mRNA and protein are barely detectable 
A

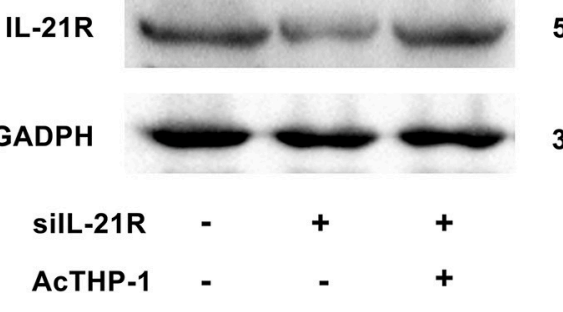

C

silL-21R AcTHP-1
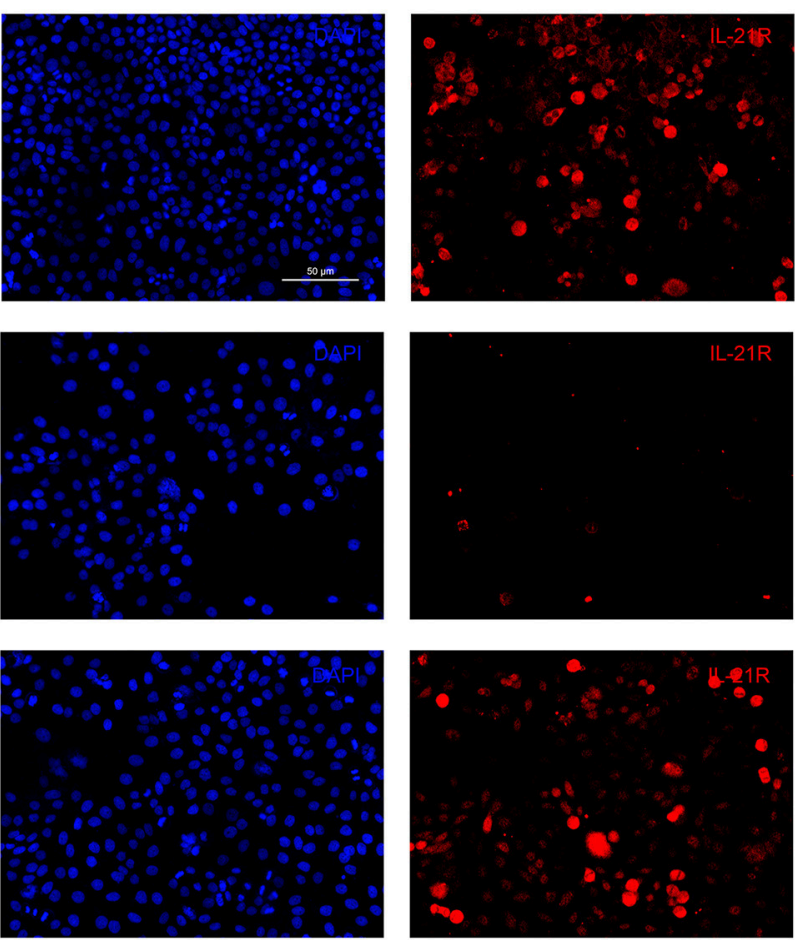

B

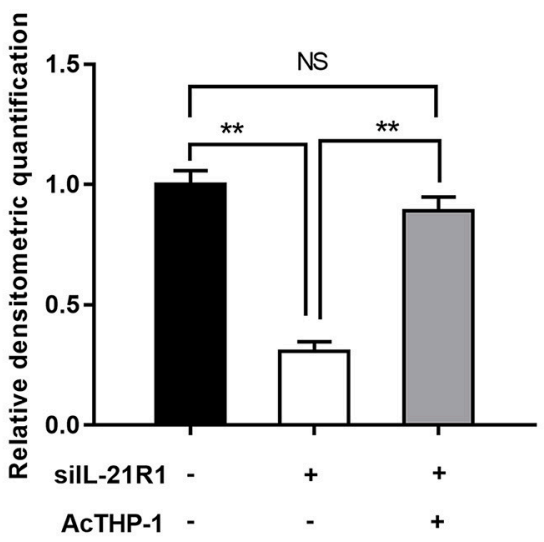

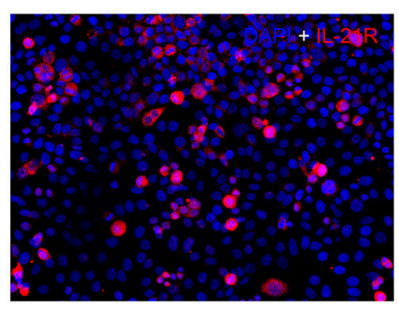
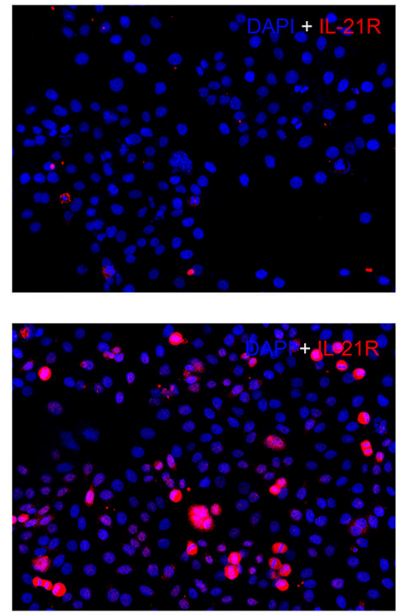

FIGURE 6 | Effect of AcTHP-1 co-culture on the expression of IL-21R in BPH-1 cells. (A) Representative Western Blot bands of IL-21R in BPH-1 cells co-cultured with or without AcTHP-1 in the absence or presence of silL-21R1. (B) Relative densitometric quantification of IL-21R in BPH-1 cells. GAPDH expression was analyzed as a loading control, results are expressed as ratio of the proteins in respect to GAPDH. Boxes, mean; bars, $\pm \mathrm{SD}$; ${ }^{\star \star} P<0.01$ vs. BPH-1cells without AcTHP-1 co-culture in the presence of silL-21R1. NS means no significance, BPH-1 cells without AcTHP-1 co-culture in the absence of silL-21R1 vs. BPH-1cells with AcTHP-1 co-culture in the presence of silL-21R1. (C) Immunofluorescence of IL-21R in BPH-1 cells. Cy3-immunofluorescence (red) indicates IL-21R expression. DAPI (blue) indicates cell nuclear staining. Merged image indicates of IL-21R and DAPI. Upper, BPH-1cells without AcTHP-1 co-culture in the absence of silL-21R1. Middle, BPH-1cells without AcTHP-1 co-culture in the presence of silL-21R1. Lower, BPH-1cells with AcTHP-1 co-culture in the presence of silL-21R1. The scale bars are $50 \mu m$.

with qRT-PCR and Western Blot in cultured stromal cells (Supplementary Figure S1). Therefore, epithelial cells were used in our subsequent studies. In addition, IL-21R expression was higher in human hyperplastic prostate tissues (Figure 1A) than normal prostate tissues, which was further determined by qRTPCR and Western Blot. As shown in Figures 1B-D, both mRNA and protein expression of IL-21R were significantly increased $(P<0.05)$ in hyperplastic prostate by 3.1 - and 2.1 -fold, respectively.

As aforementioned, the epithelial cell line BPH-1 was employed to evaluate the role of IL-21R in the development of BPH. We knocked down IL-21R expression in BPH-1 cells by using three different siRNA sequences (silL-21R 1, 2, and 3) and the mRNA expression of IL-21R was down-regulated (Figure 2A) 


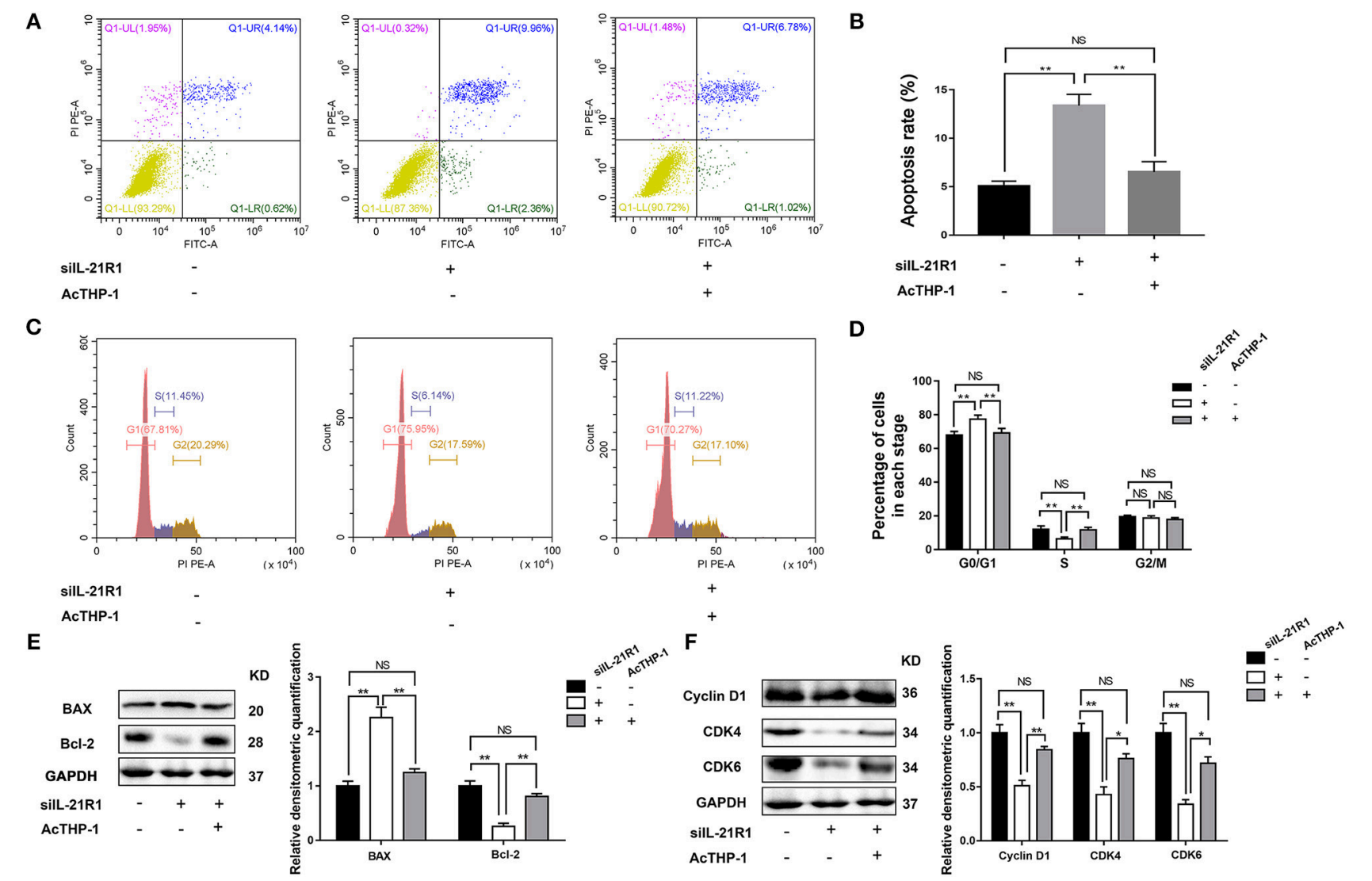

FIGURE 7 | Effect of AcTHP-1 co-culture on BPH-1 cell apoptosis and cell cycle. (A) Flow Cytometry analyses for cell apoptosis in BPH-1 cells co-cultured with or without AcTHP-1 in the absence or presence of silL-21R1. (B) Bar graph for the rate of BPH-1 cell apoptosis. Boxes, mean; bars, \pm SD; ${ }^{\star \star} P<0.01$ vs. BPH-1cells without AcTHP-1 co-culture in the presence of silL-21R1. NS means no significance, BPH-1 cells without AcTHP-1 co-culture in the absence of silL-21R1 vs. $\mathrm{BPH}-1$ cells with AcTHP-1 co-culture in the presence of silL-21R1. (C) Flow Cytometry analyses for cell cycle in BPH-1 cells co-cultured with or without AcTHP-1 in the absence or presence of silL-21R1. (D) Bar graph for the percentage of BPH-1 cells in each cell phase. Boxes, mean; bars, $\pm \mathrm{SD}$; ${ }^{\star \star} P<0.01 \mathrm{vs}$. BPH-1 cells without AcTHP-1 co-culture in the presence of silL-21R1. NS means no significance, BPH-1 cells without AcTHP-1 co-culture in the absence of silL-21R1 vs. $\mathrm{BPH}-1$ cells with AcTHP-1 co-culture in the presence of silL-21R1. (E) Left, Representative Western Blot band of cell apoptosis associated protein (BAX and Bcl-2) in $\mathrm{BPH}-1$ cells. Right, Relative densitometric quantification of cell apoptosis associated protein (BAX and Bcl-2) in BPH-1 cells. GAPDH expression was analyzed as a loading control, results are expressed as ratio of the proteins in respect to GAPDH. Boxes, mean; bars, $\pm \mathrm{SD}$; ${ }^{\star \star} P<0.01 \mathrm{vs}$. BPH-1cells without AcTHP-1 co-culture in the presence of silL-21R1. NS means no significance, BPH-1cells without AcTHP-1 co-culture in the absence of silL-21R1 vs. BPH-1 cells with AcTHP-1 co-culture in the presence of silL-21R1. (F) Left, Representative Western Blot band of cell cycle associated protein (Cyclin D1, CDK4, and CDK6) in BPH-1 cells. Right, Relative densitometric quantification of cell cycle associated protein (Cyclin D1, CDK4, and CDK6) in BPH-1 cells. GAPDH expression was analyzed as a loading control, results are expressed as ratio of the proteins in respect to GAPDH. Boxes, mean; bars, $\pm \mathrm{SD}$; ${ }^{\star} P<0.05$, ${ }^{\star \star} P<0.01 \mathrm{vs}$. BPH-1 cells without AcTHP-1 co-culture in the presence of silL-21R1. NS means no significance, BPH-1cells without AcTHP-1 co-culture in the absence of silL-21R1 vs. BPH-1cells with AcTHP-1 co-culture in the presence of silL-21R1.

by 80,74 , and $57 \%$, respectively. silL-21R1 was selected for use in further experimentation due to its highest inhibitory efficacy. Indeed, the expression of IL-21R in BPH-1 cells transfected with silL-21R1 was obviously decreased both in Western Blot study (Figures 2B,C) and immunofluorescent staining (Figure 2D). To investigate the functions of IL-21R in prostate epithelial cells, we further analyzed cell proliferation, cell apoptosis, and cell cycle progression for these IL-21R down-regulated BPH-1 cells, using MTT assay and flow cytometry analysis. MTT assay showed silL-21R1 treated BPH-1 cells grew slower than control group (Figure 3). Flow Cytometry showed an increase of cell apoptosis by $12.8 \%$ (Figures 4 A,B). Flow Cytometry also showed an increase of G0/G1 phase cells and a decrease of $S$ phase cells by 9.2 and 6.9\%, respectively (Figures 4C,D). Meanwhile, we detected the levels of proteins associated with cell apoptosis and the cell cycle, using Western Blot. BAX expression was increased while Bcl-2 expression was decreased (Figure 4E) by 2.1-folds and 72\%, respectively. Cyclin D1, CDK4, and CDK6 were all significantly decreased (Figure 4F). Furthermore, to determine whether differential expression of IL-21R altered the EMT process of BPH-1 cells, we detected the expression of proteins (E-Cad, N-Cad, and vimentin) associated with EMT by Western blot and immunofluorescent staining. As shown in Figure 5, E-Cad was up-regulated while N-Cad and vimentin were down-regulated. The results indicated that knockdown of IL-21R could inhibit the EMT process. Our data suggests that 


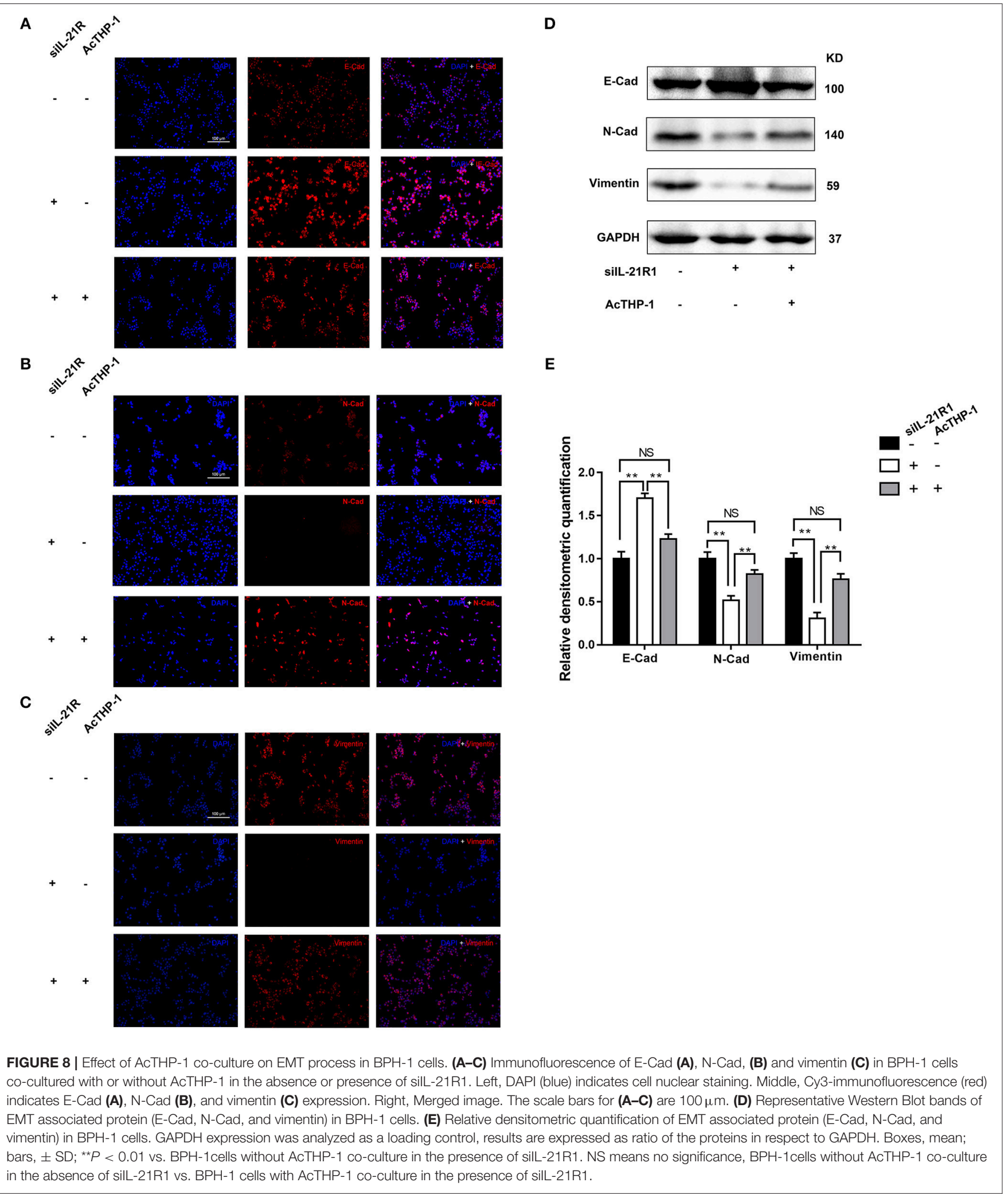

knockdown of IL-21R could significantly inhibit the proliferation of prostatic epithelium via triggering cell apoptosis and arresting the cell cycle, as well as attenuation of the EMT process.
To further determine the activity of IL-21R in the prostatic epithelial cells, we co-cultured the above transfected BPH-1 cells with or without AcTHP-1. LPS was used for differentiation 
A

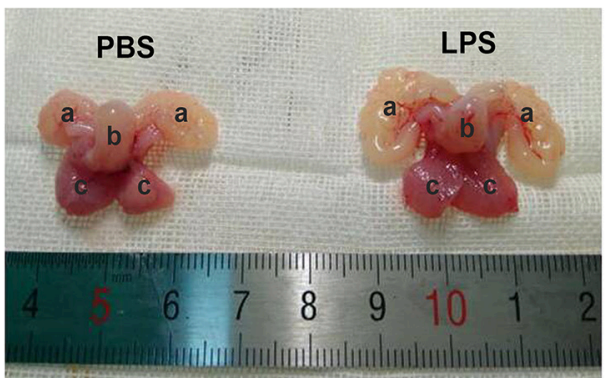

C

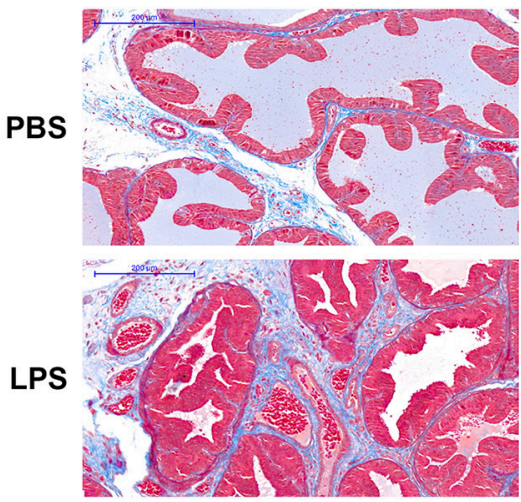

B

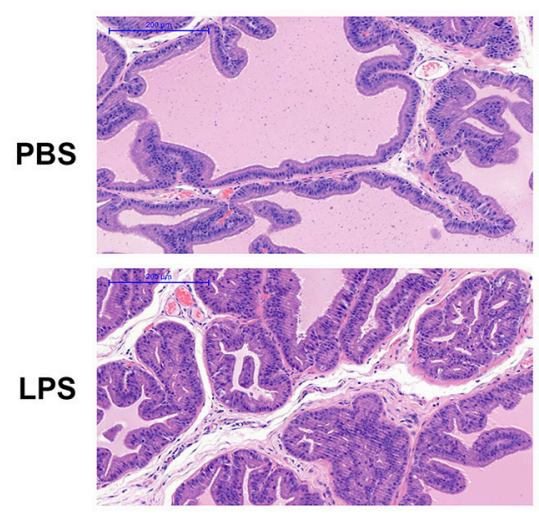

D

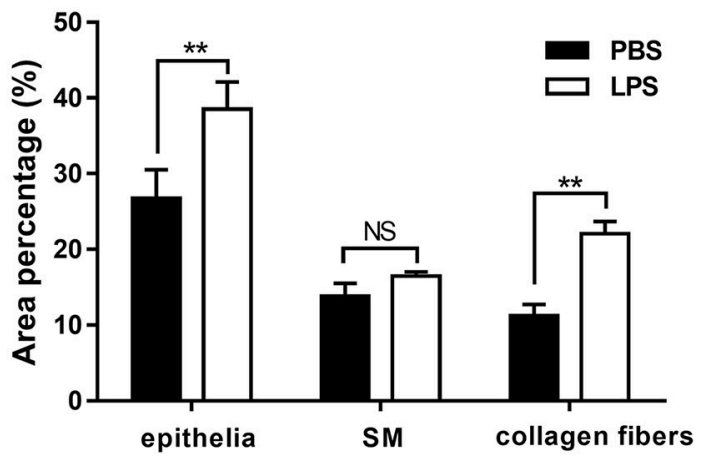

FIGURE 9 | Typical rat prostate photograph and histological examination. (A) typical prostate photograph from PBS and LPS treatment rats, (a) seminal vesicle, (b) bladder, (c) prostate. (B) Representative H-E staining of PBS and LPS treatment rat prostate. The scale bars are $200 \mu \mathrm{m}$. (C) Masson's trichrome staining of PBS and LPS treatment rat prostate, prostate epithelial cells were stained orange, SM cells were stained red and collagen fibers were stained blue. The scale bars are $200 \mu \mathrm{m}$. ( $n=8$ for each group). (D) Quantification of Masson's trichrome staining. Area percentage of different component were quantified from three random $100 \times$ fields of each tissue slices ( $n=8$ for each group). Boxes, mean; bars, \pm SD; ${ }^{\star \star} P<0.01$, NS means no significance vs. PBS.

TABLE 2 | Variation of biometric and physiological parameters in PBS and LPS injected rats.

\begin{tabular}{lccccc}
\hline & \multicolumn{2}{c}{ Body weight $\mathbf{( g )}$} & & \\
\cline { 2 - 3 } Group & Initial & Final & & $\begin{array}{c}\text { Ventral prostate } \\
\text { weight }(\mathbf{m g})\end{array}$ & Prostate index \\
\hline PBS & $270(25)$ & $315(49)$ & $250(66.7)$ & $0.79(0.00)$ \\
LPS & $268(16)$ & $319(36)$ & & $470(266.7)^{\star \star}$ & $1.50(0.01)^{\star \star}$ \\
P-value & 0.62 & 0.49 & $<0.01$ & $<0.01$ \\
\hline
\end{tabular}

$P$-values calculated by unpaired t-test. Data are mean $\pm S D$. ${ }^{\star \star} P<0.01$ vs. $P B S$.

of THP-1 cells into macrophages. To exclude the effect of THP-1 cells or LPS on BPH-1 cells, we co-cultured THP-1 cells with $\mathrm{BPH}-1$ cells or stimulated $\mathrm{BPH}-1$ cells with gradient concentration of LPS. Then, we determined the expression of IL-21R in BPH-1 cells, using the techniques of qRT-PCR and Western blot. Results showed no significant difference in IL-21R expression (Supplementary Figures S2, S3). These results suggest that THP-1 cells or LPS has no effect on IL$21 \mathrm{R}$ expression in BPH-1 cells. Therefore, AcTHP-1 cells were co-cultured with BPH-1 cells for follow-up experiments. As shown in Figure 6, co-culturing with AcTHP-1 cells per se heavily up-regulated IL-21R. Accordingly, flow cytometry showed cell apoptosis and cell cycle arrest induced by silencing IL-21R were reversed in co-cultured cells (Figures 7A-D). Consistently, the levels of proteins (BAX, Bcl-2, Cyclin D1, CDK4, and CDK6) involved in cell apoptosis and the cell cycle were reversed by co-culturing with AcTHP-1 (Figures 7E,F). Additionally, immunofluorescent staining and Western Blotting showed protein expressions of E-Cad, N-Cad, and vimentin associated with EMT process were also reversed with E-Cad decreased while N-Cad and vimentin increased (Figure 8). Again, our data indicated that IL-21R could modulate cell apoptosis and the cell cycle, as well as the EMT process, via an inflammatory microenvironment in the prostate.

Finally, the role of IL-21R was determined in vivo. With LPS intraprostatic injection, a prostatitis rat model was established. This model exhibited inflammatory infiltration and hemorrhage (Figure 9B) shown by $\mathrm{H} \& \mathrm{E}$ Staining. Interestingly, our 2-week prostatitis rats were concomitant with prostatic hyperplasia. As shown in Figure 9A and Table 2, rat prostates were significantly enlarged with the weight of the ventral prostate increased by 
A

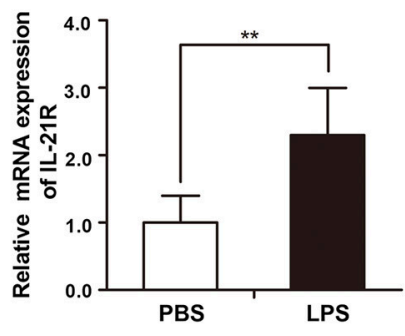

D

PBS
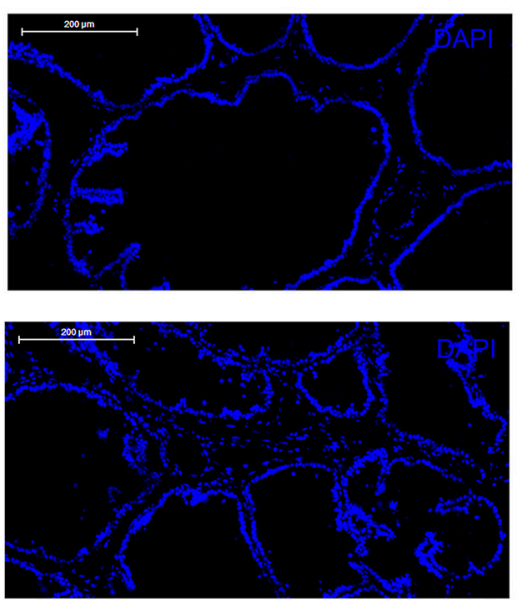

B

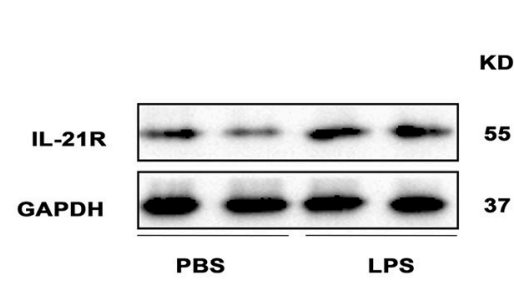

C
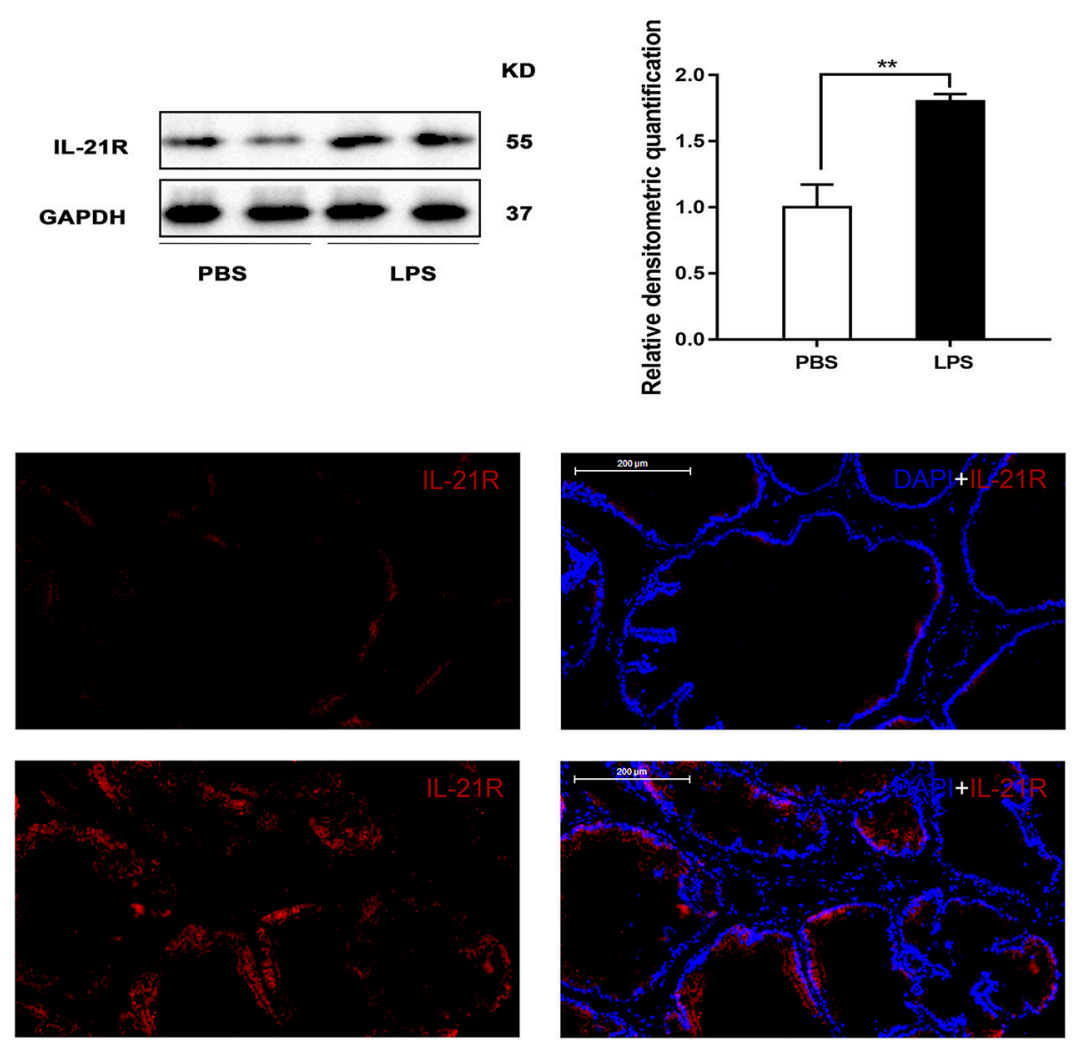

FIGURE 10 | The expression and immunofluorescence of IL-21R in rat prostate. (A) The mRNA expression of IL-21R in PBS and LPS treated prostate $(n=8$ for each group); (B) representative Western blot band of IL-21R in PBS and LPS treated rat prostate. (C) Relative densitometric quantification of IL-21R in PBS and LPS treated rat prostate. GAPDH expression was analyzed as a loading control, results are expressed as ratio of IL-21R in respect to GAPDH. Boxes, mean; bars, \pm SD; ${ }^{\star *} P<0.01$ vs. PBS. (D) Immunofluorescence of IL-21R. Left, DAPI (blue) indicates nuclear staining. Middle, Cy3-immunofluorescence (red) indicates IL-21R. Right, Merged image. The scale bars are $200 \mu \mathrm{m}$.

1.9-fold and the prostate index [prostate wet weight (mg)/ body weight $(\mathrm{g})]$ increased by 2.0 -fold $(P<0.01)$ in the LPS injected rats group. No difference for the body weight was observed between the 2 groups (Table 2). In addition, it was observed the number of acini increased, lumen space decreased, epithelium thickened, and stroma densified (Figure 9B) in the LPS injected group as shown in H \& E staining. Masson's trichrome stain in further showed the epithelium and the collagen fibers component increased with no change in the stroma (Figures 9C,D). Similar to human BPH, IL-21R was mainly localized in the epithelium of rat prostate (Figure 10D) and its expression was upregulated with the levels of mRNA (Figure 10A) and protein (Figures 10B,C) both enhanced in LPS injected group, when compared to normal rat prostate tissues. In addition, we detected apoptosis, cyclin and EMT proteins in this rat model by Western blot and immunofluorescent staining. As shown in Figures 11, 12, BAX was decreased while Bcl-2 was increased (Figures 11A,B). Cyclin D1, CDK4, and CDK6 were all significantly increased (Figures 11C,D). E-Cad was down-regulated, while N-Cad and vimentin were up-regulated (Figure 12). These results are consistent with that observed in the cell line model.

\section{DISCUSSION}

Our novel data showed IL-21R was mainly localized in prostate epithelium and it was upregulated in hyperplastic prostate tissues. Our study also demonstrated that IL-21R plays roles in the development of $\mathrm{BPH}$ via inhibiting cell apoptosis and modulating cell cycle progression, as well as enhancing the EMT process in response to inflammatory stimuli.

IL-21R is primarily expressed in hematopoietic cells but it has also been found to exist in non-immune cells such as fibroblasts, endothelial cells, keratinocytes, Hodgkin lymphoma cells, and breast cancer cells $(20,22,23)$. In this current study, we found that IL-21R was highly expressed in prostate tissues, especially in the epithelium. Moreover, it was upregulated in the prostates from $\mathrm{BPH}$ patients concomitant with prostatitis. Consistent with IL-21R, differential expression of other IL-receptors have been observed between $\mathrm{BPH}$ and normal prostate tissues, such as IL-15R (26). Additionally, previous studies have suggested IL2, IL-4, and IL-15 are partly secreted by epithelial cells in response to inflammatory stimuli at the onset and during the progression of $\mathrm{BPH}(8,13,15)$. Although it was known that IL-21 is mainly released from T-lymphocytes, it has not been 
A

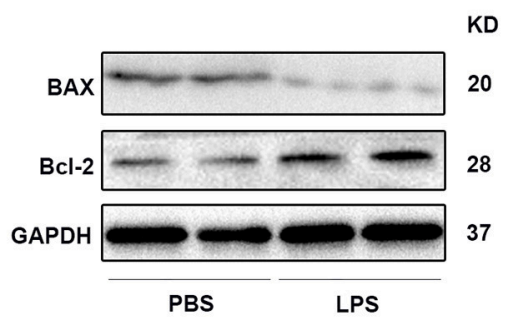

C

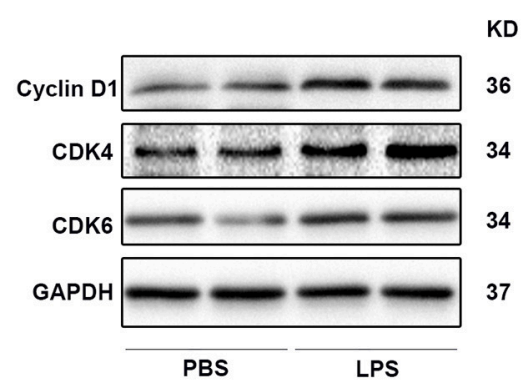

B

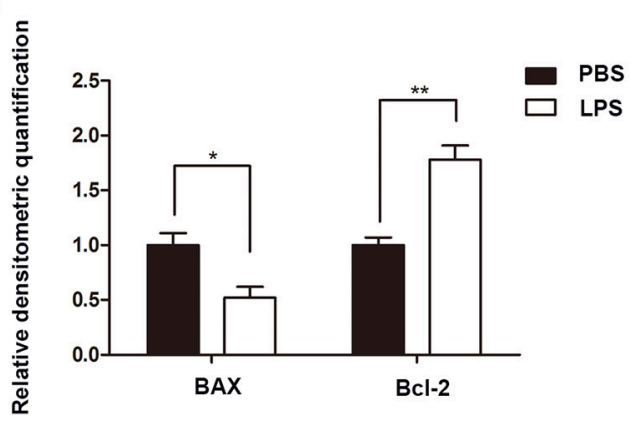

D

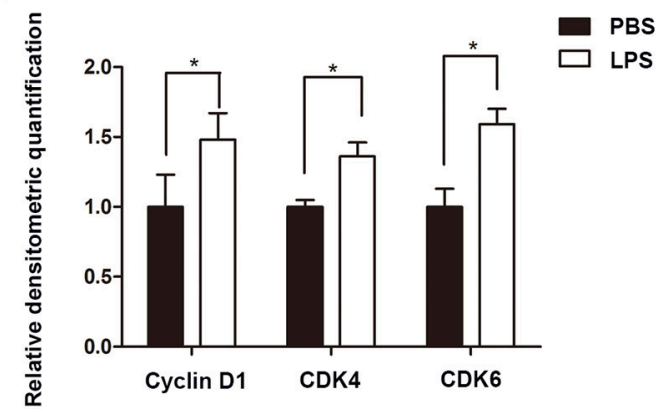

FIGURE 11 | The expression of apoptosis and cyclin proteins in rat prostate. (A) Representative Western Blot band of BAX and Bcl-2 in PBS and LPS treatment rat prostate. (B) Relative densitometric quantification of BAX and Bcl-2 in PBS and LPS treatment rat prostate. GAPDH expression was analyzed as a loading control, results are expressed as ratio of the proteins in respect to GAPDH. Boxes, mean; bars, $\pm \mathrm{SD}$; ${ }^{\star} P<0.05$ vs. LPS. (C) Representative Western Blot band of Cyclin D1, CDK4, and CDK6 in PBS and LPS treatment rat prostate. (D) Relative densitometric quantification of Cyclin D1, CDK4, and CDK6 in PBS and LPS treatment rat prostate. GAPDH expression was analyzed as a loading control, results are expressed as ratio of the proteins in respect to GAPDH. Boxes, mean; bars, \pm SD; ${ }^{\star} P<0.05,{ }^{\star \star} P<0.01$ vs. PBS.

determined whether IL-21, similar to IL-2, IL-4, and IL-15, is also partly secreted by epithelial cells.

We further explored the mechanisms of IL-21R in the development of BPH. As IL-21R was mainly expressed in the epithelium, the cultured human prostate epithelium cell line BPH-1 was used. When the expression of IL-21R in BPH1 was knocked down, the apoptosis rate was increased while the cell cycle was arrested, which were demonstrated by flow cytometry and related pathway proteins. In addition, the EMT process was inhibited when IL-21R was silenced. On the other hand, when the silL-21R1 transfected cells were co-cultured with AcTHP-1 which could release cytokines, IL-21R expression was up-regulated and the aforementioned processes were per se reversed. Therefore, our data suggests that IL-21R possibly mediates prostatic cell apoptosis, cell cycle and the EMT process during the inflammatory microenvironment. Similarly, previous studies have shown that IL-21 attracts regulatory T-cells via upregulation of macrophage inflammatory protein- $3 \alpha$ and protects cells from apoptosis via activation of STAT3 signaling pathways in IL-21 $\mathrm{R}^{+}$Hodgkin lymphoma cells (29). A recent study also showed that IL-21 increased the proliferation of IL-21R ${ }^{+}$MDA231 breast cancer cells but not that of other breast cancer cells (20). EMT is regarded as a conserved cellular process that allows the polarized and generally immotile epithelial cells to convert to motile mesenchymal cells.

A number of studies have suggested that BPH development involves accumulation of mesenchymal-like cells derived from the prostatic epithelium via EMT (5-7). Given that BPH is perceived as an immune-mediated inflammatory disease, chronic inflammation may directly stimulate the development of $\mathrm{BPH}$ $(8-10,30)$ and macrophages are the major component of the prostate inflammatory infiltrates (16). A previous study has supposed macrophages secrete cytokines, such as TGF $\beta$, to induce the proliferation and EMT process of $\mathrm{BPH}-1$ cells via co-culture of BPH-1 cells with macrophages (31). LPS was established as a chemical inducer to differentiate THP-1 cells into macrophages (32). Therefore, LPS was used for differentiation of THP-1 cells in our study. Our study found THP-1 cells had no effect on IL-21R expression in BPH-1 cells. It is because THP-1 is a human leukemia monocytic cell line and these cells are often described as being in an activation state in in vitro experiments, which can be obtained by stimulating THP1 cells with inflammatory activators, for instance, LPS, or proinflammatory cytokines (33-35). Our data is consistent with the previous study that macrophages, which differentiate from THP-1 cells, induced EMT in BPH development (31). Moreover, 


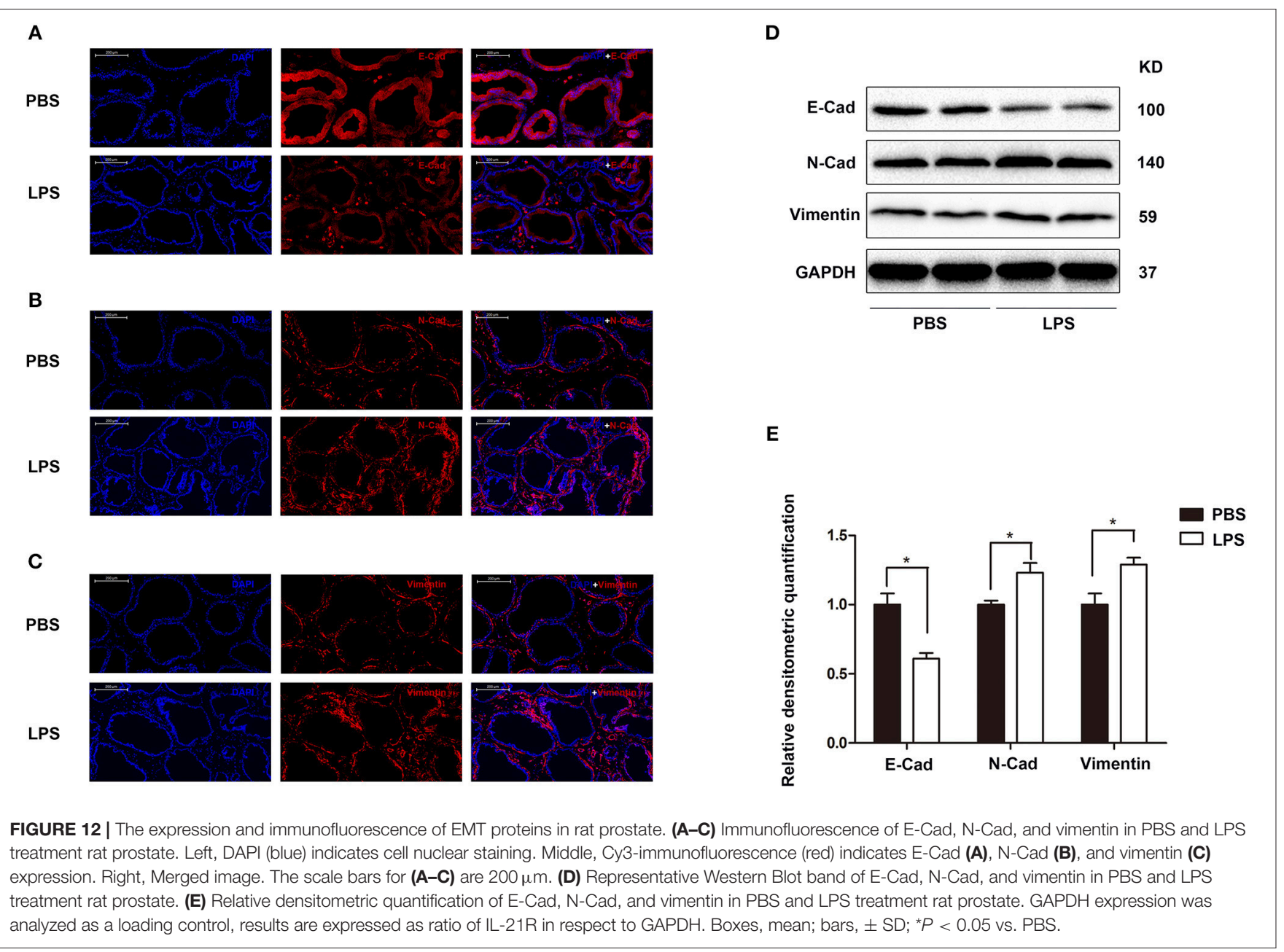

IL-21R expression was not changed in $\mathrm{BPH}-1$ cells which were stimulated with a gradient concentration of LPS. It is also consistent with the previous study that LPS has no direct effect on prostate cells (36). Indeed, the current study found macrophages reversed the silencing of IL-21R related processes when coculture was performed. However, the exact cytokines binding to IL-21R and the underling pathways of activating IL-21R in the inflammatory environment, although intriguing, remain to be elucidated.

We further extended our study in vivo. We injected LPS into rat prostates for 14 days. LPS did indeed produce prostatitis and concomitant prostatic hyperplasia. Consistent with human $\mathrm{BPH}$ and our in vitro cell proliferation study, IL-21R was upregulated in the prostate of the LPS induced prostatitis and $\mathrm{BPH}$ rat model. More specifically, the expression of apoptosis, cyclin, and EMT proteins in this rat model are altered in a manner consistent with that seen in the cell line model. It has been determined that LPS activates the immune system through stimulating pro-inflammatory cytokines and growth factors $(37,38)$. In addition, it has been suggested that LPS/TLR4 (Toll-like receptor 4 ) signaling enhances the TGF$\beta$ response during prostatic hyperplasia (36). Similarly, the activation of the expression of cytokines and growth factors was observed in prostatitis and BPH model induced with LPS injected into the rat prostate and mouse urethra (17, 39). Previous studies also showed that there was co-localization of IL-21R and VEGF in the keratinocytes of patients with skin sclerosis and it was demonstrated that VEGF production was modulated by IL-21 through IL-21R (40, 41), suggesting IL-21R is associated with inflammation and proliferation. However, it is premature to attribute the observed effects on the differential expression of IL-21R. It may be that IL$21 \mathrm{R}$ upregulation is a marker of chronic inflammation/BPH downstream of other factors central to the development of the pathology. Therefore, the effect of LPS injection on prostate biology in IL-21R knockout mice is of great interest for future investigation.

In summary, this is the first study to demonstrate the expression and functional activities of IL-21R in the prostate. IL-21R is mainly localized in prostate epithelium and it is upregulated in hyperplastic prostate tissues. Moreover, IL-21R appears to be involved in the development of $\mathrm{BPH}$ via modulation of cell apoptosis and cell cycle progression, as well as the EMT process in the inflammatory 
microenvironment. Thus, our data suggests that IL-21R could be a promsing new therapeutic target for the treatment of $\mathrm{BPH}$.

\section{AUTHOR CONTRIBUTIONS}

DX, PC, and HX contributed equally to this work. XZ, DX, PC, XW, and MD designed the experiments. DX and HX finished the experiments. DX wrote the first draft. DX and PC analyzed the results. $\mathrm{XZ}$ critically revised drafts of the manuscript. $\mathrm{XZ}$ provided important intellectual input and approved the final version for publication.

\section{FUNDING}

This study was supported by National Natural Science Foundation of China (N.81160086, N.81270843, and N.81770757).

\section{ACKNOWLEDGMENTS}

We thank the staff at Zhongnan Hospital of Wuhan University for their help in completing the study. Additional thanks go to Lushun Yuan for his help in completing the study.

\section{REFERENCES}

1. Bianchi-Frias D, Vakar-Lopez F, Coleman IM, Plymate SR, Reed MJ, Nelson PS. The effects of aging on the molecular and cellular composition of the prostate microenvironment. PLoS ONE (2010) 5:e12501. doi: 10.1371/journal.pone.0012501

2. Wei JT, Calhoun E, Jacobsen SJ. Urologic diseases in america project: benign prostatic hyperplasia. J Urol. (2008) 179(Suppl. 5):S75-80. doi: 10.1016/j.juro.2008.03.141

3. Vuichoud C, Loughlin KR. Benign prostatic hyperplasia: epidemiology, economics and evaluation. Can J Urol. (2015) 22 (Suppl. 1):1-6.

4. Timms BG, Hofkamp LE. Prostate development and growth in benign prostatic hyperplasia. Differentiation (2011) 82:173-83. doi: 10.1016/j.diff.2011.08.002

5. Alonso-Magdalena P, Brossner C, Reiner A, Cheng G, Sugiyama N, Warner $\mathrm{M}$, et al. A role for epithelial-mesenchymal transition in the etiology of benign prostatic hyperplasia. Proc Natl Acad Sci USA. (2009) 106:2859-63. doi: 10.1073/pnas.0812666106

6. Slabakova E, Pernicova Z, Slavickova E, Starsichova A, Kozubik A, Soucek K. TGF-beta1-induced EMT of non-transformed prostate hyperplasia cells is characterized by early induction of SNAI2/Slug. Prostate (2011) 71:1332-43. doi: $10.1002 /$ pros. 21350

7. Hu S, Yu W, Lv TJ, Chang CS, Li X, Jin J. Evidence of TGFbetal mediated epithelial-mesenchymal transition in immortalized benign prostatic hyperplasia cells. Mol Membr Biol. (2014) 31:103-10. doi: 10.3109/09687688.2014.894211

8. Kramer G, Mitteregger D, Marberger M. Is benign prostatic hyperplasia (BPH) an immune inflammatory disease? Eur Urol. (2007) 51:1202-16. doi: 10.1016/j.eururo.2006.12.011

9. Wang L, Yang JR, Yang LY, Liu ZT. Chronic inflammation in benign prostatic hyperplasia: implications for therapy. Med Hypotheses (2008) 70:1021-3. doi: 10.1016/j.mehy.2007.08.022

10. Gandaglia G, Briganti A, Gontero P, Mondaini N, Novara G, Salonia A, et al. The role of chronic prostatic inflammation in the pathogenesis and

\section{SUPPLEMENTARY MATERIAL}

The Supplementary Material for this article can be found online at: https://www.frontiersin.org/articles/10.3389/fendo. 2019.00004/full\#supplementary-material

Supplementary Figure S1 | The expression of IL-21R in prostate cells. (A) The mRNA expression of IL-21R in BPH-1 and WPMY-1 cells. (B) Representative Western Blot band of IL-21R in BPH-1 and WPMY-1 cells. (C) Relative densitometric quantification of IL-21R in BPH-1 and WPMY-1 cells. GAPDH expression was analyzed as a loading control, results are expressed as ratio of $\mathrm{IL}-21 \mathrm{R}$ in respect to GAPDH. Boxes, mean; bars, $\pm \mathrm{SD}$; ${ }^{*} P<0.01 \mathrm{vs}$. $\mathrm{BPH}-1$.

Supplementary Figure S2 | Effect of THP-1 co-culture on the expression of $\mathrm{IL}-21 \mathrm{R}$ in $\mathrm{BPH}-1$ cells. (A) The mRNA expression of IL-21R in BPH-1 cells co-cultured with or without THP-1cells. (B) Representative Western Blot bands of IL-21R in BPH-1 cells co-cultured with or without AcTHP-1cells. (C) Relative densitometric quantification of IL-21R in $\mathrm{BPH}-1$ cells. GAPDH expression was analyzed as a loading control, results are expressed as ratio of the proteins in respect to GAPDH. Boxes, mean; bars, \pm SD; NS means no significance, $\mathrm{BPH}-1$ cells without THP-1 co-culture vs. BPH-1cells with THP-1 co-culture.

Supplementary Figure S3 | Effect of LPS on the mRNA expression of IL-21R in $\mathrm{BPH}-1$ cells. The mRNA expression of IL-21R in $\mathrm{BPH}-1$ cells treated with gradient concentration of LPS. Boxes, mean; bars, \pm SD; NS means no significance vs. control.

Supplementary Table S1 | List of siRNA sequences.

Supplementary Table S2 | List of primary antibodies used for western blot.

Supplementary Table S3 | List of secondary antibodies used for western blot.

progression of benign prostatic hyperplasia (BPH). BJU Int. (2013) 112:43241. doi: $10.1111 /$ bju. 12118

11. Nickel JC, Roehrborn CG, O'Leary MP, Bostwick DG, Somerville MC, Rittmaster RS. The relationship between prostate inflammation and lower urinary tract symptoms: examination of baseline data from the REDUCE trial. Eur Urol. (2008) 54:1379-84. doi: 10.1016/j.eururo.2007.11.026

12. Alcaraz A, Hammerer P, Tubaro A, Schroder FH, Castro R. Is there evidence of a relationship between benign prostatic hyperplasia and prostate cancer? Findings of a literature review. Eur Urol. (2009) 55:864-73. doi: 10.1016/j.eururo.2008.11.011

13. De Nunzio C, Kramer G, Marberger M, Montironi R, Nelson W, Schroder F, et al. The controversial relationship between benign prostatic hyperplasia and prostate cancer: the role of inflammation. Eur Urol. (2011) 60:106-17. doi: 10.1016/j.eururo.2011.03.055

14. Di Silverio F, Gentile V, De Matteis A, Mariotti G, Giuseppe V, Luigi PA, et al. Distribution of inflammation, pre-malignant lesions, incidental carcinoma in histologically confirmed benign prostatic hyperplasia: a retrospective analysis. Eur Urol. (2003) 43:164-75. doi: 10.1016/S0302-2838(02)00548-1

15. De Nunzio C, Presicce F, Tubaro A. Inflammatory mediators in the development and progression of benign prostatic hyperplasia. Nat Rev Urol. (2016) 13:613-26. doi: 10.1038/nrurol.2016.168

16. Robert G, Descazeaud A, Nicolaiew N, Terry S, Sirab N, Vacherot $\mathrm{F}$, et al. Inflammation in benign prostatic hyperplasia: a 282 patients' immunohistochemical analysis. Prostate (2009) 69:1774-80. doi: $10.1002 /$ pros.21027

17. Kim HJ, Park JW, Cho YS, Cho CH, Kim JS, Shin HW, et al. Pathogenic role of HIF-1alpha in prostate hyperplasia in the presence of chronic inflammation. Biochim Biophys Acta (2013) 1832:183-94. doi: 10.1016/j.bbadis.2012.09.002

18. Ozaki K, Kikly K, Michalovich D, Young PR, Leonard WJ. Cloning of a type I cytokine receptor most related to the IL-2 receptor beta chain. Proc Natl Acad Sci USA. (2000) 97:11439-44. doi: 10.1073/pnas.200360997

19. Parrish-Novak J, Dillon SR, Nelson A, Hammond A, Sprecher C, Gross $\mathrm{JA}$, et al. Interleukin 21 and its receptor are involved in NK cell expansion and regulation of lymphocyte function. Nature (2000) 408:57-63. doi: $10.1038 / 35040504$ 
20. Wang LN, Cui YX, Ruge F, Jiang WG. Interleukin 21 and its receptor play a role in proliferation, migration and invasion of breast cancer cells. Cancer Genomics Proteomics (2015) 12:211-21.

21. Davis MR, Zhu Z, Hansen DM, Bai Q, Fang Y. The role of IL-21 in immunity and cancer. Cancer Lett. (2015) 358:107-14. doi: 10.1016/j.canlet.2014.12.047

22. Jungel A, Distler JH, Kurowska-Stolarska M, Seemayer CA, Seibl R, Forster A, et al. Expression of interleukin-21 receptor, but not interleukin-21, in synovial fibroblasts and synovial macrophages of patients with rheumatoid arthritis. Arthritis Rheum. (2004) 50:1468-76. doi: 10.1002/art.20218

23. Distler JH, Jungel A, Kowal-Bielecka O, Michel BA, Gay RE, Sprott H, et al. Expression of interleukin-21 receptor in epidermis from patients with systemic sclerosis. Arthritis Rheum. (2005) 52:856-64. doi: 10.1002/art. 20883

24. Liu L, Li Q, Han $\mathrm{P}$, Li X, Zeng H, Zhu Y, et al. Evaluation of interleukin-8 in expressed prostatic secretion as a reliable biomarker of inflammation in benign prostatic hyperplasia. Urology (2009) 74:340-4. doi: 10.1016/j.urology.2009.02.064

25. Mechergui YB, Ben Jemaa A, Mezigh C, Fraile B, Ben Rais N, Paniagua $\mathrm{R}$, et al. The profile of prostate epithelial cytokines and its impact on sera prostate specific antigen levels. Inflammation (2009) 32:202-10. doi: 10.1007/s10753-009-9121-7

26. Handisurya A, Steiner GE, Stix U, Ecker RC, Pfaffeneder-Mantai S, Langer D, et al. Differential expression of interleukin-15, a pro-inflammatory cytokine and T-cell growth factor, and its receptor in human prostate. Prostate (2001) 49:251-62. doi: 10.1002/pros.10020

27. Penna G, Fibbi B, Amuchastegui S, Cossetti C, Aquilano F, Laverny G, et al. Human benign prostatic hyperplasia stromal cells as inducers and targets of chronic immuno-mediated inflammation. J Immunol. (2009) 182:4056-64. doi: 10.4049/jimmunol.0801875

28. Zhang W, Zang N, Jiang Y, Chen P, Wang X, Zhang X. Upregulation of phosphodiesterase type 5 in the hyperplastic prostate. Sci Rep. (2015) 5:17888. doi: $10.1038 /$ srep 17888

29. Lamprecht B, Kreher S, Anagnostopoulos I, Johrens K, Monteleone G, Jundt F, et al. Aberrant expression of the Th2 cytokine IL-21 in Hodgkin lymphoma cells regulates STAT3 signaling and attracts Treg cells via regulation of MIP-3alpha. Blood (2008) 112:3339-47. doi: 10.1182/blood-2008-01134783

30. Kramer G, Marberger M. Could inflammation be a key component in the progression of benign prostatic hyperplasia? Curr Opin Urol. (2006) 16:25-9. doi: 10.1097/01.mou.0000193368.91823.1b

31. Lu T, Lin WJ, Izumi K, Wang X, Xu D, Fang LY, et al. Targeting androgen receptor to suppress macrophage-induced EMT and benign prostatic hyperplasia (BPH) development. Mol Endocrinol. (2012) 26:1707-15. doi: $10.1210 /$ me.2012-1079
32. Bhattacharya A, Agarwal M, Mukherjee R, Sen P, Sinha DK. 3D micro-environment regulates NF-kappabeta dependent adhesion to induce monocyte differentiation. Cell Death Dis. (2018) 9:914. doi: 10.1038/s41419-018-0993-z

33. Gordon S. Alternative activation of macrophages. Nat Rev Immunol. (2003) 3:23-35. doi: 10.1038/nri978

34. Mosser DM. The many faces of macrophage activation. J Leukoc Biol. (2003) 73:209-12. doi: 10.1189/jlb.0602325

35. Taylor PR, Martinez-Pomares L, Stacey M, Lin HH, Brown GD, Gordon S. Macrophage receptors and immune recognition. Annu Rev Immunol. (2005) 23:901-44. doi: 10.1146/annurev.immunol.23.021704.115816

36. He Y, Ou Z, Chen X, Zu X, Liu L, Li Y, et al. LPS/TLR4 signaling enhances TGF-beta response through downregulating BAMBI during prostatic hyperplasia. Sci Rep. (2016) 6:27051. doi: 10.1038/srep27051

37. Pei Z, Lin D, Song $X$, Li H, Yao H. TLR4 signaling promotes the expression of VEGF and TGFbetal in human prostate epithelial PC3 cells induced by lipopolysaccharide. Cell Immunol. (2008) 254:20-7. doi: 10.1016/j.cellimm.2008.06.007

38. Iglesias-Gato D, Carsten T, Vesterlund M, Pousette A, Schoop R, Norstedt G. Androgen-independent effects of Serenoa repens extract (Prostasan(R)) on prostatic epithelial cell proliferation and inflammation. Phytother Res. (2012) 26:259-64. doi: 10.1002/ptr.3537

39. Dos Santos Gomes FO, Oliveira AC, Ribeiro EL, da Silva BS, Dos Santos LA, de Lima IT, et al. Intraurethral injection with LPS: an effective experimental model of prostatic inflammation. Inflamm Res. (2018) 67:43-55. doi: 10.1007/s00011-017-1094-7

40. Monteleone G, Pallone F, Macdonald T. Interleukin-21 (IL-21)-mediated pathways in T cell-mediated disease. Cytokine Growth Factor Rev. (2009) 20:185-91. doi: 10.1016/j.cytogfr.2009.02.002

41. Kim H, Kang JS, Lee WJ. The production IL-21 and VEGF in UVBirradiated human keratinocyte cell line, HaCaT. Immune Netw. (2010) 10:7580. doi: $10.4110 /$ in. 2010.10 .2 .75

Conflict of Interest Statement: The authors declare that the research was conducted in the absence of any commercial or financial relationships that could be construed as a potential conflict of interest.

Copyright (c) $2019 \mathrm{Xu}$, Chen, Xiao, Wang, DiSanto and Zhang. This is an open-access article distributed under the terms of the Creative Commons Attribution License (CC $B Y)$. The use, distribution or reproduction in other forums is permitted, provided the original author(s) and the copyright owner(s) are credited and that the original publication in this journal is cited, in accordance with accepted academic practice. No use, distribution or reproduction is permitted which does not comply with these terms. 